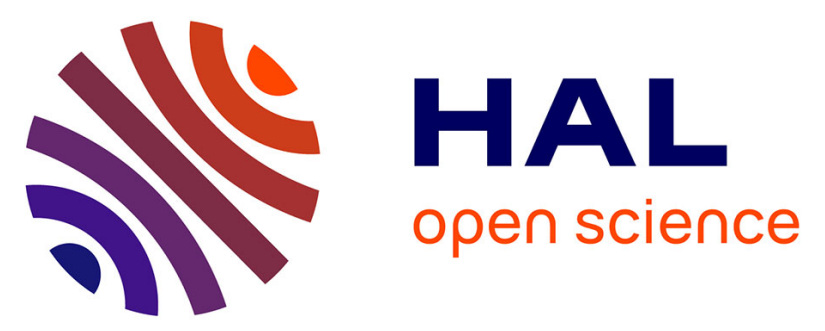

\title{
Tunable Surface Structuration of Silicon by Metal Assisted Chemical Etching with Pt Nanoparticles under Electrochemical Bias
}

Encarnacion Torralba-Penalver, Sylvain Le Gall, R. Lachaume, Vincent Magnin, Joseph El Harari, Mathieu Halbwax, Jean-Pierre Vilcot, Christine Cachet-Vivier, S. Bastide

\section{To cite this version:}

Encarnacion Torralba-Penalver, Sylvain Le Gall, R. Lachaume, Vincent Magnin, Joseph El Harari, et al.. Tunable Surface Structuration of Silicon by Metal Assisted Chemical Etching with Pt Nanoparticles under Electrochemical Bias. ACS Applied Materials \& Interfaces, 2016, ACS, Applied Materials \& Interfaces, 8, pp.31375. 10.1021/acsami.6b09036 . hal-01392805

\section{HAL Id: hal-01392805 https://hal.science/hal-01392805}

Submitted on 12 Mar 2020

HAL is a multi-disciplinary open access archive for the deposit and dissemination of scientific research documents, whether they are published or not. The documents may come from teaching and research institutions in France or abroad, or from public or private research centers.
L'archive ouverte pluridisciplinaire HAL, est destinée au dépôt et à la diffusion de documents scientifiques de niveau recherche, publiés ou non, émanant des établissements d'enseignement et de recherche français ou étrangers, des laboratoires publics ou privés. 


\title{
Tunable Surface Structuration of Silicon by Metal Assisted Chemical Etching with Pt Nanoparticles under Electrochemical Bias
}

\author{
Encarnación Torralba, ${ }^{\dagger, \perp}$ Sylvain Le Gall, ${ }^{\ddagger}, \perp$ Raphaël Lachaume, ${ }^{\ddagger}$ Vincent Magnin, ${ }^{\S}$ Joseph Harari, ${ }^{\S}$ \\ Mathieu Halbwax, ${ }^{\S}$ Jean-Pierre Vilcot, ${ }^{\S}$ Christine Cachet-Vivier, ${ }^{\dagger}$ and Stéphane Bastide ${ }^{*},{ }^{\dagger}$ \\ ${ }^{\dagger}$ Institut de Chimie et des Matériaux Paris-Est, CNRS, Université Paris-Est, 2-8 rue Henri Dunant, 94320 Thiais, France \\ ${ }^{\ddagger}$ Group of electrical engineering - Paris, UMR CNRS 8507, Centrale Supélec, Univ. Paris-Sud, Université Paris-Saclay, Sorbonne \\ Universités, UPMC Université Paris 06, 3 \& 11 rue Joliot-Curie, Plateau de Moulon, 91192 Gif-sur-Yvette CEDEX, France \\ ${ }^{\S}$ Institut d'Électronique, de Microélectronique et de Nanotechnologie, UMR CNRS 8520, Université de Lille 1 - Sciences et \\ Technologies, Avenue Henri Poincaré, CS 60069, 59652 Villeneuve d'Ascq cedex, France
}

Supporting Information

ABSTRACT: An in-depth study of metal assisted chemical etching (MACE) of p-type c-Si in $\mathrm{HF} / \mathrm{H}_{2} \mathrm{O}_{2}$ aqueous solutions using Pt nanoparticles as catalysts is presented. Combination of cyclic voltammetry, open circuit measurements, chronoamperometry, impedance spectroscopy, and 2D band bending modeling of the metal/semiconductor/electrolyte interfaces at the nanoscale and under different etching conditions allows gaining physical insights into this system. Additionally, in an
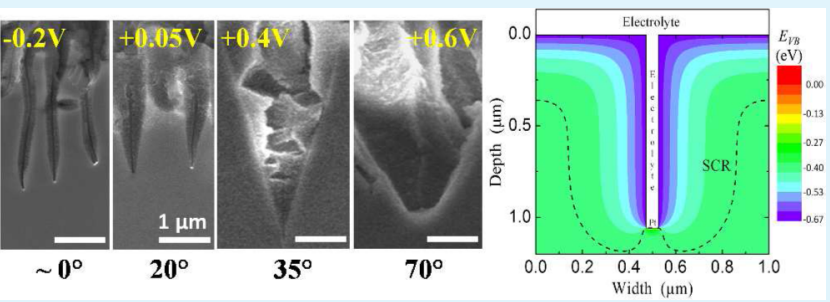
attempt to mimic the etching conditions, the modeling has been performed with a positively biased nanoparticle buried in the Si substrate. Following these findings, the application of an external polarization during etching is introduced as a novel efficient approach for achieving straightforward control of the pore morphology by acting upon the band bending at the Si/electrolyte junction. In this way, nanostructures ranging from straight mesopores to cone-shaped macropores are obtained as the Si sample is biased from negative to positive potentials. Remarkably, macroscopic cone-shaped pores in the $1-5 \mu \mathrm{m}$ size range with a high aspect ratio (L/W 1.6) are obtained by this method. This morphology leads to a reduction of the surface reflectance below 5\% over the entire VIS-NIR domain, which outperforms macrostructures made by state of the art texturization techniques for Si solar cells.

KEYWORDS: metal assisted chemical etching, c-Si, platinum, cyclic voltammetry, impedance spectroscopy, 2D band bending modeling, Si texturization, cone-shaped macropores

\section{INTRODUCTION}

During the past decade, metal assisted chemical etching (MACE) of $\mathrm{Si}$ has attracted considerable attention as an efficient method to produce Si nanostructures with high aspect ratio. Nanowires, nanogratings, and nanopores have been synthesized by MACE and their potential applications have been tested in fields ranging from solar energy conversion to chemical and biological sensing.

Noble metals, including $\mathrm{Ag}, \mathrm{Au}, \mathrm{Pt}, \mathrm{Pd}$, and $\mathrm{Rh}$ are known to be effective catalysts for MACE. ${ }^{1-3}$ Using single nanoparticles (NPs), etching with $\mathrm{Ag}$ results in the formation of straight mesopores with smooth walls whose diameter matches the particle size. ${ }^{4,5} \mathrm{Ag}$ is therefore the metal of choice for highly localized etching and formation of well-defined nanostructures (e.g., Si nanowires). On the contrary, Pt leads to the formation of cone-shaped pores with walls fully covered by porous $\mathrm{Si}^{6}$ The behavior of $\mathrm{Au}$ seems to be intermediate between that of $\mathrm{Ag}$ and Pt. The etch rate increases in the following order: $\mathrm{Ag}<$ $\mathrm{Au}<\mathrm{Pt}$. Although well-known, these differences have started to be addressed only recently. Yae has established that the etch rates depend on the difference in catalytic activities of the metal for $\mathrm{O}_{2}$ reduction in the $\mathrm{HF} / \mathrm{O}_{2}$ system. ${ }^{1}$ Kolasinki has recently brought to attention the importance of the Si/metal Schottky junction properties on the (de)localized character of etching. ${ }^{7,8}$ Depending on the metal work function, the junction can be rectifying $(\mathrm{Ag})$ or not $(\mathrm{Au}, \mathrm{Pt})$ and thus can modify hole $\left(\mathrm{h}^{+}\right)$ injection into $\mathrm{Si}$.

Despite the fact that Pt has been associated with MACE of Si since the beginning, the mechanisms for the formation of coneshaped pores by $\mathrm{Pt}$ particles and the dependence of their morphology on the etching conditions have not been studied in great detail so far (contrarily to $\mathrm{Ag}$ ). A better understanding of Pt-based MACE, and its peculiarities compared to other metal etching systems, is therefore needed. To the best of our knowledge, MACE was first reported by Zhang et al. in 1993. In their work, n-type $\mathrm{Si}$ samples in contact with an $\mathrm{Hg}$ pool were immersed in HF solutions with dissolved $\mathrm{O}_{2}$ and under illumination. Strong etching occurred when a $\mathrm{Pt}$ wire was

Received: July 22, 2016

Accepted: October 26, 2016

Published: October 26, 2016 
placed in contact with the $\mathrm{Hg}$ pool and the electrolyte. At the end of the 1990s, electroless $\mathrm{Si}$ etching obtained by $\mathrm{Pt}$ deposition in $\mathrm{HF} /$ " $\mathrm{Pt}$ tV salts" leading to porous $\mathrm{Si}$ formation was reported by Gorostiza et al. ${ }^{10,11}$ and by $\mathrm{Li}$ and Bohn who coined the term MACE with their work on porous Si formation with platinized $\mathrm{Si}$ surfaces. ${ }^{12,13}$ At the same time, galvanic etching of $\mathrm{Si}$ with $\mathrm{Pt}$ in $\mathrm{HF} / \mathrm{H}_{2} \mathrm{O}_{2}$ was proposed by the group of Kelly as an electroless technique to form porous $\mathrm{Si}$ on large scale samples for application in microelectronics. ${ }^{14,15}$

The discovery that metal NPs actually dig pores into Si substrates was eventually made by Tsujino and Matsumura with $\mathrm{Ag}^{4}$ and Pt NPs ${ }^{6}$ and by Peng et al. with Ag for the elaboration of $\mathrm{Si}$ nanowire networks. ${ }^{16}$ In the case of $\mathrm{Pt}$, etching in HF/ $\mathrm{H}_{2} \mathrm{O}_{2}$ with NPs (50 nm in diameter) resulted in the formation of pores consisting of an empty core of the same diameter as the Pt NP and a large surrounding porous Si region exhibiting a cone-shaped morphology. ${ }^{6}$ Using Pt beads of micrometer size and a longer etching time, cone-shaped macropores with a thin layer of porous $\mathrm{Si}$ on the walls were formed. ${ }^{17}$ To explain these results and the difference with the straight and smooth mesopores obtained by MACE with Ag NPs, the authors suggested that an easy transport of $\mathrm{h}^{+}$across the $\mathrm{Pt} / \mathrm{Si}$ interface together with a strong catalytic activity of $\mathrm{Pt}$ was leading to porous $\mathrm{Si}$ formation at the pore walls via diffusion of injected $\mathrm{h}^{+}$. The cone-shaped morphology was attributed to the fact that the porous Si layer formed at the walls becomes thicker as a function of time, i.e., with a thickness gradient from the top to the tip of the pore. In more recent reports, injection and diffusion of $\mathrm{h}^{+}$from the metal catalysts have been considered to be key parameters to explain the etched structure morphologies obtained by MACE. ${ }^{18-20}$

In this work, MACE of p-type c-Si using Pt NPs as catalyst is investigated both experimentally and theoretically. Special emphasis is paid to the study and interpretation of the electrochemical processes governing the mechanisms of pore formation and their dependence on the etching conditions. Combination of electrochemical characterization (cyclic voltammetry, open circuit measurements, chronoamperometry, and impedance spectroscopy) and $2 \mathrm{D}$ band bending modeling of the metal/semiconductor/electrolyte interfaces demonstrates that the particular features of $\mathrm{Pt}$ etching can be explained on the basis of the ohmic nature of the $\mathrm{Pt} / \mathrm{Si}$ contact which induces an anodic polarization of the Si bulk. To the best of our knowledge, this is the first time in the field of MACE that a rigorous modeling of the band modulation under etching conditions (electrostatically biased and buried NP) is presented.

In line with this mechanism, the application of an external potential during MACE is investigated as a simple way to achieve a straightforward control of the pore morphology, by modifying the band bending at the $\mathrm{Si}$ /electrolyte junction. A similar approach has been reported by Chourou et al. where MACE in $\mathrm{HF} / \mathrm{H}_{2} \mathrm{O}_{2}$ with $\mathrm{Ag}, \mathrm{Pd}$, and $\mathrm{Pt}$ has been studied on lightly doped $\mathrm{p}^{-}$-type $\mathrm{Si}$ under small anodic polarization. ${ }^{21}$ In the case of $\mathrm{Pt}$, straight macropores were formed under these etching conditions. We show here that with p-type $\mathrm{Si}$ and at higher anodic potential, high aspect ratio cone-shaped pores can be obtained, with potential applications in photovoltaics due to the very low reflectance of the resulting surface morphology $(\mathrm{R} \sim 3 \%)$.

\section{EXPERIMENTAL SECTION}

Reagents. Polished, single crystalline (100) p-type (boron) and n-type (phosphorus) Si wafers, 350-450 $\mu \mathrm{m}$ thick, with a resistivity of $1-3 \Omega \mathrm{cm}$ were used. $30 \% \mathrm{H}_{2} \mathrm{O}_{2}, 96-97 \% \mathrm{H}_{2} \mathrm{SO}_{4}$, $40 \% \mathrm{HF}$, and $65 \% \mathrm{HNO}_{3}$ reagents of analytical grade (VWR chemicals) were employed as received for cleaning and etching $\mathrm{Si}$ and for porous Si dissolution. $\mathrm{H}_{2} \mathrm{PtCl}_{6} \cdot 6 \mathrm{H}_{2} \mathrm{O}$ (99.9\%, SigmaAldrich) was used for $\mathrm{Si}$ electroless platinization. Dilution and cleaning were performed with $18.2 \mathrm{M} \Omega \mathrm{cm}$ Ultrapure water (Millipore).

Electroless Metallization of Si Samples. Si wafers ( $p$ or $\mathrm{n}$ type) were cleaved into $1 \times 1 \mathrm{~cm}^{2}$ pieces and cleaned for 20 min in piranha solution $\left(3: 1 \mathrm{v} / \mathrm{v}\right.$ concentrated $\mathrm{H}_{2} \mathrm{SO}_{4} / 30 \%$ $\mathrm{H}_{2} \mathrm{O}_{2}$ ) to eliminate organic residues. After copious rinsing with ultrapure water, the samples were immersed for $5 \mathrm{~min}$ in HF 1 $M$ to remove surface oxides and to hydrogenate the Si surface. Pt NPs were then deposited on the cleaned Si substrate by immersion in an aqueous solution of $1 \mathrm{mM} \mathrm{H}_{2} \mathrm{PtCl}_{6}$ and 90 $\mathrm{mM} \mathrm{HF}$ for 30 to $300 \mathrm{~s}$.

Metal Assisted Etching. Etching was performed just after platinization in an aqueous solution of $\mathrm{HF}$ and $\mathrm{H}_{2} \mathrm{O}_{2}$. In all cases, a ratio $\rho=[\mathrm{HF}] /\left([\mathrm{HF}]+\left[\mathrm{H}_{2} \mathrm{O}_{2}\right]\right)$ was set to $0.75 .{ }^{22}$

Electrochemical Characterization. All the electrochemical experiments were performed in a homemade O-ring threeelectrode cell. $\mathrm{p}$ or $\mathrm{n}$ type $\mathrm{Si}$ (bare or platinized) were used as working electrode, a $\mathrm{KCl}$ saturated calomel electrode (SCE), protected from the $\mathrm{HF}$ solution by a $\mathrm{KCl}$ saturated agar-agar bridge, was used as reference and a Pt wire as counter electrode. The geometrical area of $\mathrm{Si}$ exposed to the solution in the electrochemical cell was $0.38 \mathrm{~cm}^{2}$. The electrical contact at the back side of the Si sample was made by rubbing InGa alloy onto it. Owing to the HF concentrations used (typically $0.5 \mathrm{M}$ or above) no supporting electrolyte was added. Approximately 20 $\mathrm{mL}$ of solution were used for the electrochemical experiments. All potentials are referred to SCE.

For the open circuit potential (OCP) determinations, the initial solution of $0.5 \mathrm{M} \mathrm{HF}$ was degassed for $10 \mathrm{~min}$ under $\mathrm{Ar}$ prior to the experiment to remove dissolved oxygen. Ar atmosphere was maintained throughout the experiment. Given the negligible oxidizing effect of $\mathrm{O}_{2}$ in the presence of $\mathrm{H}_{2} \mathrm{O}_{2}$, the working solutions were not degassed for the MACE experiments.

For impedance spectroscopy measurements, the amplitude of the ac signal was $10 \mathrm{mV} \mathrm{rms}$ and several frequencies ranging from 10 to $100 \mathrm{kHz}$ were used. The differential capacity $C$ was determined from the imaginary part of the complex impedance $\left(C=-1 /\left(2 \pi f Z^{\prime \prime}\right)\right)$ in the frequency range for which the system behaves primarily as a combination of capacitive circuit elements (phase angle greater than $80^{\circ}$ ). All impedance measurements were carried out in the dark.

Instrumentation. Cyclic voltammetry, chronoamperometry and impedance spectroscopy were performed with a PGSTAT 20 potentiostat/galvanostat Metrohm Autolab, equipped with GPES and FRA software. Scanning electron microscopy (SEM) images were obtained with a Merlin FEG microscope from Zeiss. The optical reflectivity measurements were performed in the 350-1500 nm range using a Hitachi UV-vis-NIR 4001 spectrophotometer fitted with an integrating sphere.

\section{RESULTS AND DISCUSSION}

Platinization of Si Samples. Electroless metal deposition on $\mathrm{Si}$ is a well-known procedure based on a localized galvanic 
displacement reaction. In the case of $\mathrm{Pt}$, the reduction of a metal complex, such as $\mathrm{PtCl}_{6}{ }^{2-}$ (from $\mathrm{H}_{2} \mathrm{PtCl}_{6}$ ), coupled to the simultaneous dissolution (in the divalent state) of nearby $\mathrm{Si}$ atoms, leads to metal deposition: ${ }^{11}$

at cathodic sites: ${ }^{23}$

$$
\mathrm{PtCl}_{6}{ }^{2-}+4 \mathrm{e}^{-} \rightarrow \mathrm{Pt}+6 \mathrm{Cl}^{-} ; E^{0}=0.74 \mathrm{~V} / \mathrm{SHE}
$$

at anodic sites:

$$
\mathrm{Si}+4 \mathrm{HF}_{2}^{-} \rightarrow \mathrm{SiF}_{6}^{2-}+2 \mathrm{HF}+\mathrm{H}_{2}+2 \mathrm{e}^{-} ; E^{0}=-1.20 \mathrm{~V} / \mathrm{SHE}
$$

In order to find the conditions leading to the deposition of well-defined Pt NPs, different metallization times were tested. Figure 1 shows SEM plane views of p-type (100) Si samples
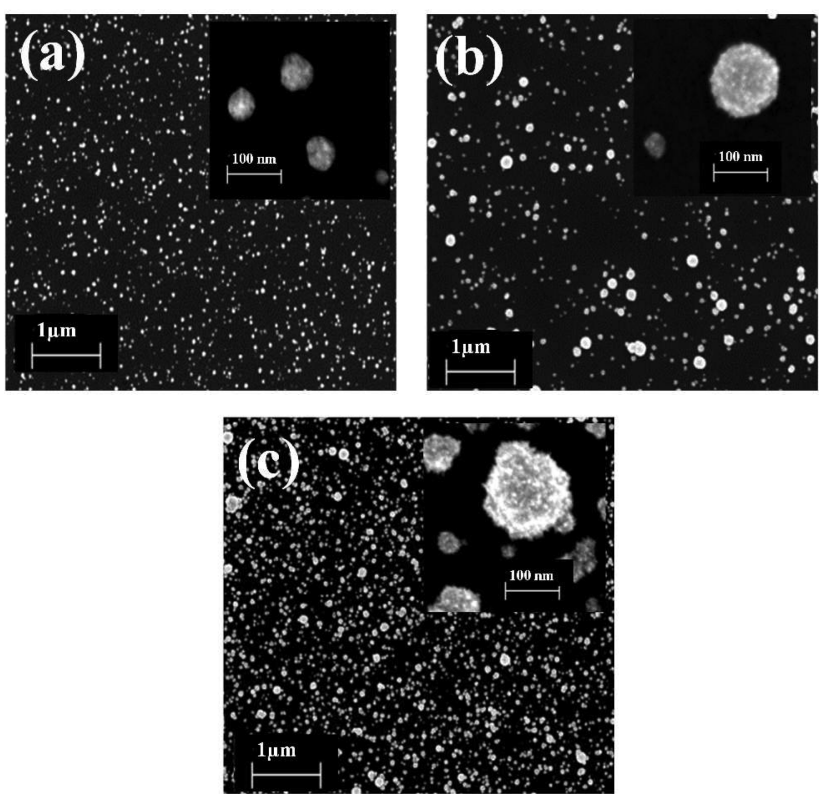

Figure 1. SEM images of platinized p-type (100) Si surfaces obtained by immersion in an aqueous solution of $1 \mathrm{mM} \mathrm{H}_{2} \mathrm{PtCl}_{6}$ and $90 \mathrm{mM}$ HF for $30 \mathrm{~s}(\mathrm{a}), 120 \mathrm{~s}$ (b), and $300 \mathrm{~s}$ (c).

with Pt NPs deposited by immersion in a metallization bath containing $1 \mathrm{mM}$ of $\mathrm{H}_{2} \mathrm{PtCl}_{6}$ and $90 \mathrm{mM}$ of $\mathrm{HF}$, for three different times (cf. Experimental Section for details).

SEM observations reveal a $\mathrm{Si}$ surface loaded by nearly spherical Pt NPs with average diameters ranging approximately from 25 to $100 \mathrm{~nm}$ for metallization times of 30 to $300 \mathrm{~s}$, respectively. As the metallization time increases, the granular morphology of the resulting NPs becomes more accentuated and the spherical shape is lost. A duration of 2 min was chosen for all the subsequent experiments. Under these conditions, $\mathrm{Pt}$ NPs with an average diameter of $50 \mathrm{~nm}$ are obtained (cf. Figure S1 in SI), with a metal coverage of approximately $12 \%$.

MACE and Pore Morphology. MACE uses noble metals to induce local oxidation and reduction reactions under open circuit. The metal deposited on the Si surface serves as a local cathode to catalyze the reduction of oxidants (usually $\mathrm{H}_{2} \mathrm{O}_{2}$ ). The produced $\mathrm{h}^{+}$are then injected into the $\mathrm{Si}$ valence band, which initiates the oxidation of surface atoms that eventually become soluble as $\mathrm{SiF}_{6}{ }^{2-}$ complexes in the acidic HF solution. This results in the removal of $\mathrm{Si}$ without net consumption of the metal. ${ }^{24}$
In the particular case of $\mathrm{Pt}$ and by analogy with the mechanism proposed for $\mathrm{Ag}^{22}$ the overall reaction of MACE in a solution of $\mathrm{H}_{2} \mathrm{O}_{2}$ and $\mathrm{HF}$ can be written as

$$
\mathrm{Si}+6 \mathrm{HF}+\frac{n}{2} \mathrm{H}_{2} \mathrm{O}_{2} \stackrel{\mathrm{Pt}}{\rightarrow} \mathrm{H}_{2} \mathrm{SiF}_{6}+n \mathrm{H}_{2} \mathrm{O}+\left[\frac{4-n}{2}\right] \mathrm{H}_{2}
$$

where $n$ varies from 2 to 4 as the Si dissolution regime evolves from porous $\mathrm{Si}$ formation to electropolishing. ${ }^{25}$

Cross sectional SEM images of typical cone-shaped macropores obtained by MACE of p-type c-Si with Pt NPs are given in Figure 2. To obtain these structures, the platinized p-type Si samples were immersed for $10 \mathrm{~min}$ in a solution of $3.63 \mathrm{M} \mathrm{HF}$ and $1.2 \mathrm{M} \mathrm{H}_{2} \mathrm{O}_{2}(\rho=0.75)$.
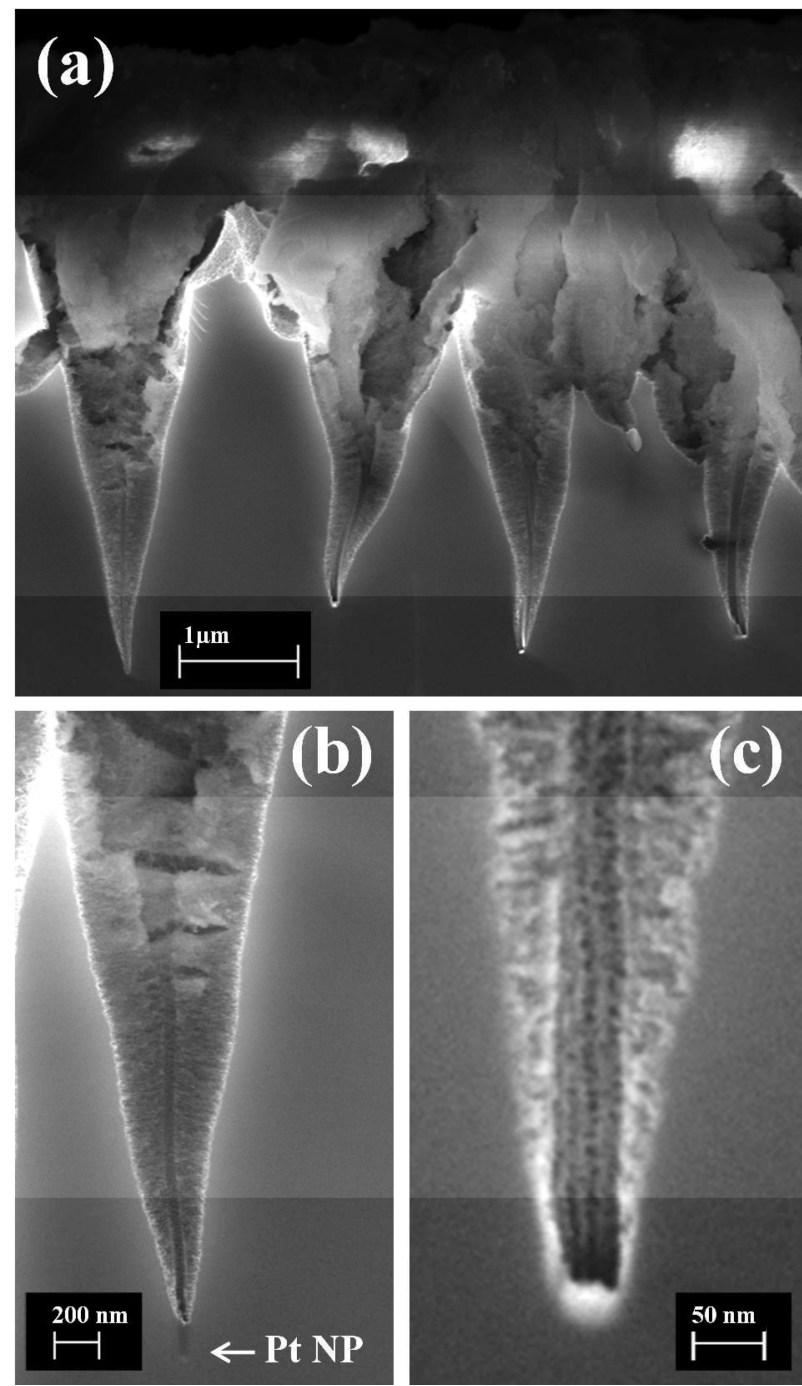

Figure 2. SEM images in cross section of p-type (100) Si samples after MACE with Pt NPs (increased magnification from a to $c$ ).

As already described by Tsujino and Matsumura, ${ }^{6}$ a thick porous Si layer covers both the surface and the surrounding of the inner core etched by the NP (Figure 2a). After $10 \mathrm{~min}$ etching, the depth reached by the Pt NPs is around $6 \mu \mathrm{m}$ (with respect to the top porous $\mathrm{Si}$ surface), corresponding to an etch rate of $\sim 0.6 \mu \mathrm{m} / \mathrm{min}$. Figure $2 \mathrm{~b}$ focuses on a single macropore, where the $\mathrm{Pt} \mathrm{NP}$ is distinguishable slightly below the pore tip (since it was not cleaved right in the middle). 
The cone angle $\alpha$ defined by the porous $\mathrm{Si} / \mathrm{c}-\mathrm{Si}$ interface is $\sim 20^{\circ}$. Interestingly, the high magnification image of another pore tip in Figure $2 c$ shows that the empty core has the exact diameter of the NP and reveals that there is no porous $\mathrm{Si}$ beneath it.

This is in contrast to MACE experiments with Au networks dedicated to form $\mathrm{Si}$ nanowires, for which etching involves the formation of a porous Si layer beneath the Au film. ${ }^{26}$ The lack of underlying porous $\mathrm{Si}$ in the present case, as well as for MACE with Ag NPs, seems to indicate that electropolishing governs dissolution at the $\mathrm{Pt} / \mathrm{Si}$ interface. However, for a 3.63 M HF solution, the critical current density $\left(J_{\mathrm{PS}}\right)$ is $\sim 75 \mathrm{~mA}$ / $\mathrm{cm}^{225}$ whereas the obtained etch rate of $0.6 \mu \mathrm{m} / \mathrm{min}$ corresponds to a current of $\sim 21 \mathrm{~mA} / \mathrm{cm}^{2}$ (assuming $3 \mathrm{~h}^{+}$/ dissolved Si atom), i.e., etching at the level of the NP should be in the porous $\mathrm{Si}$ formation regime. This discrepancy could be due to the actual presence of a very thin porous Si layer that is constantly etched by the NP as it sinks into the bulk or more likely to a lower HF concentration at the tip of the growing pore than in the bulk of the electrolyte due to mass transport limitation. In addition, the metal is an obstacle for the access of the electrolyte to the etching front and may also lower the effective HF concentration. ${ }^{27}$ This could imply a much lower $J_{\mathrm{PS}}$ value and thus explain the lack of porous $\mathrm{Si}$ at the pore tip. As a matter of fact, experiments performed on (111) oriented and multicrystalline p-type Si show that the Pt NPs follow $<100>$ directions [unpublished results, cf. S5 in SI] which is in an indication of etching at $J_{\mathrm{PS}}{ }^{25}$

When comparing Figures $1 \mathrm{~b}$ and $2 \mathrm{a}$, it is interesting to note that the density of macropores at the surface is much lower than the initial density of Pt NPs (by a factor of $\sim 20$ ). Only a fraction of the initial Pt NPs are found at the etching front, the others being embedded in the top porous Si layer due to the overlapping of macropores. In line with these findings, it is assumed that an increase of the Pt coverage (as in Figure 1c) would lead to the same macropore density after etching. Conversely, it has been observed that decreasing it eventually leads to the formation of one macropore per Pt NP (i.e., isolated macropores, results not shown here).

Electrochemical Characterization. Cyclic voltammetry and open circuit potential (OCP, or rest potential) measurements were performed for "in situ" electrochemical characterization of the $\mathrm{Pt} / \mathrm{Si} /$ electrolyte system. Figure 3 shows the evolution of OCP in the dark for bare and platinized Si (dotted blue and solid red lines, respectively), in contact with a solution of $\mathrm{HF}(0.5 \mathrm{M})$ and upon addition of $\mathrm{H}_{2} \mathrm{O}_{2}(0.17 \mathrm{M}, \rho=0.75)$. To test the effect of illumination on the electrochemical response, light was sequentially switched on and off during the experiment.

In presence of HF only, the OCPs in the dark of bare and platinized $\mathrm{Si}$ are close $(-0.36$ against $-0.30 \mathrm{~V}$ vs SCE, respectively). The OCP can be identified as a redox mixed potential resulting from the equilibration of positive and negative charge transfers at anodic and cathodic surface sites of the $\mathrm{Si}$ electrode. As pointed out in several studies from Chemla's group, in the absence of a redox couple and dissolved $\mathrm{O}_{2}$ in solution, this charge transfer corresponds to proton discharge $\left(\mathrm{H}^{+}+\mathrm{e}^{-}+\mathrm{Si} \rightarrow \mathrm{Si}-\mathrm{H}, E_{\mathrm{H}}=-0.06 \mathrm{pH} \mathrm{V}\right.$ vs SHE $)$ and $\mathrm{Si}$ oxidation $\left(\mathrm{Si}+\mathrm{F}^{-} \rightarrow \mathrm{Si}-\mathrm{F}+\mathrm{e}^{-}, E_{\mathrm{Si}}=-1.2 \mathrm{~V}\right.$ vs $\left.\mathrm{SHE}\right){ }^{28}$ Under these conditions, the OCP can be described by

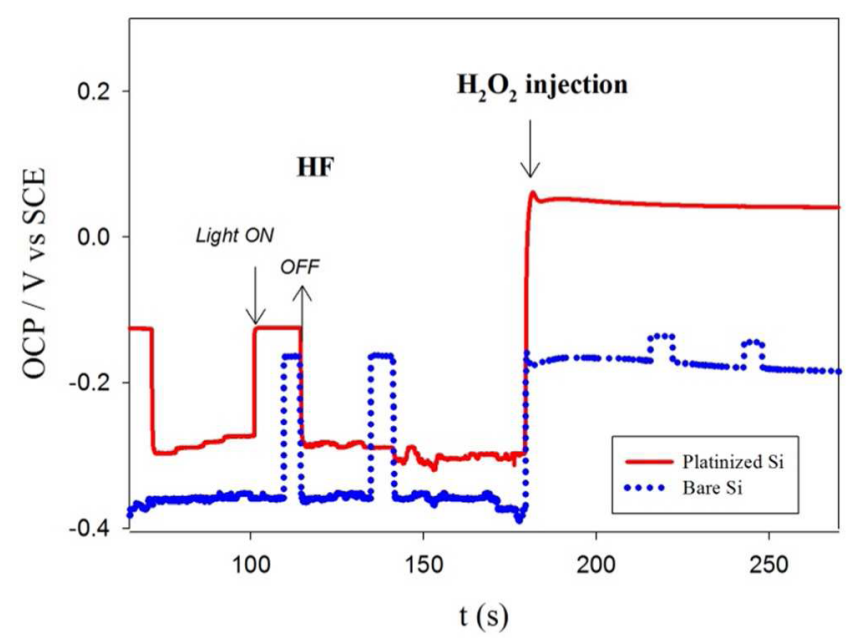

Figure 3. OCP measurements with bare and platinized $\mathrm{Si}$ in the dark and under illumination immersed in a solution of $0.5 \mathrm{M} \mathrm{HF}$ and upon $\mathrm{H}_{2} \mathrm{O}_{2}$ addition to reach $0.17 \mathrm{M}(\rho=0.75)$.

$$
E_{\mathrm{OCP}}=\frac{1}{2}\left(E_{\mathrm{Si}}+E_{\mathrm{H}}\right)+\left(\frac{k T}{e}\right) \ln \left(\frac{j_{0 \mathrm{C}}}{j_{0 \mathrm{~A}}}\right)
$$

where $j_{0 \mathrm{C}}$ and $j_{\mathrm{OA}}$ are the cathodic and anodic exchange current densities, characteristic of the charge transfer rate on Si surface cathodic and anodic sites (cf. [22] for a detailed explanation of eq 4). The slightly more positive potential of platinized Si can then be ascribed to a higher $j_{0 C}$ resulting from the catalytic activity of Pt toward proton discharge, or more likely in our case toward the reduction of $\mathrm{O}_{2}$ traces in the reaction media $\left(\mathrm{O}_{2}+2 \mathrm{H}^{+}+2 \mathrm{e}^{-} \rightarrow \mathrm{H}_{2} \mathrm{O}_{2}, E^{\circ}=+0.68 \mathrm{~V}\right.$ vs SHE$)$ since simple Ar bubbling was used without further precautions. ${ }^{29}$

Upon addition of $\mathrm{H}_{2} \mathrm{O}_{2}$, both bare and platinized $\mathrm{Si}$ experience a shift in the OCP toward positive values coinciding with the beginning of electroless Si dissolution. This shift can also be ascribed to an increase in $j_{0 \mathrm{C}}$ due to the strong oxidizing character of $\mathrm{H}_{2} \mathrm{O}_{2}\left(\mathrm{H}_{2} \mathrm{O}_{2}+2 \mathrm{H}^{+}+2 \mathrm{e}^{-} \rightarrow \mathrm{H}_{2} \mathrm{O}+\mathrm{O}_{2}, E^{\circ}=+1.77\right.$ $\mathrm{V}$ vs SHE). The OCP is considerably more positive in the presence of $\mathrm{Pt}(+0.05$ against $-0.16 \mathrm{~V}$ vs SCE for bare $\mathrm{Si}$ at the end of the experiment) which reflects the catalytic activity of $\mathrm{Pt}$ for $\mathrm{H}_{2} \mathrm{O}_{2}$ reduction during MACE.

In presence of $\mathrm{HF}$, the effect of light is to shift the OCP toward positive potentials by $0.20 \mathrm{~V}$ (bare $\mathrm{Si}$ ) and $0.14 \mathrm{~V}$ (platinized $\mathrm{Si}$ ), while after $\mathrm{H}_{2} \mathrm{O}_{2}$ addition, scarce or no light influence is observed. This absence of photoresponse in the presence of $\mathrm{H}_{2} \mathrm{O}_{2}$ can be attributed to the high level of $\mathrm{h}^{+}$ injection at the surface, such that the change in carrier concentrations by photogeneration becomes negligible. ${ }^{30}$ This effect is strongly accentuated for the platinized sample.

The analysis of the potential dependence of the MACE process was carried out by means of cyclic voltammetry $(\mathrm{CV})$ measurements in the dark. Figure 4 shows the CVs corresponding to bare and platinized $\mathrm{Si}$ (dotted blue and solid red lines, respectively) in a solution of $0.5 \mathrm{M} \mathrm{HF}$ and 0.17 $\mathrm{M} \mathrm{H}_{2} \mathrm{O}_{2}(\rho=0.75)$, together with an enlarged view of the OCP zone as inset.

The current/potential curve of bare $\mathrm{Si}$ in $\mathrm{HF} / \mathrm{H}_{2} \mathrm{O}_{2}$ is surprisingly identical to the response of p-type $\mathrm{Si}$ in $\mathrm{HF}^{31}$ Under anodic polarization above OCP $(-0.16 \mathrm{~V}$ vs SCE), an exponential increase of the current density corresponding to the porous $\mathrm{Si}$ formation regime $\left(\mathrm{h}^{+}\right.$diffusion control) leads to 


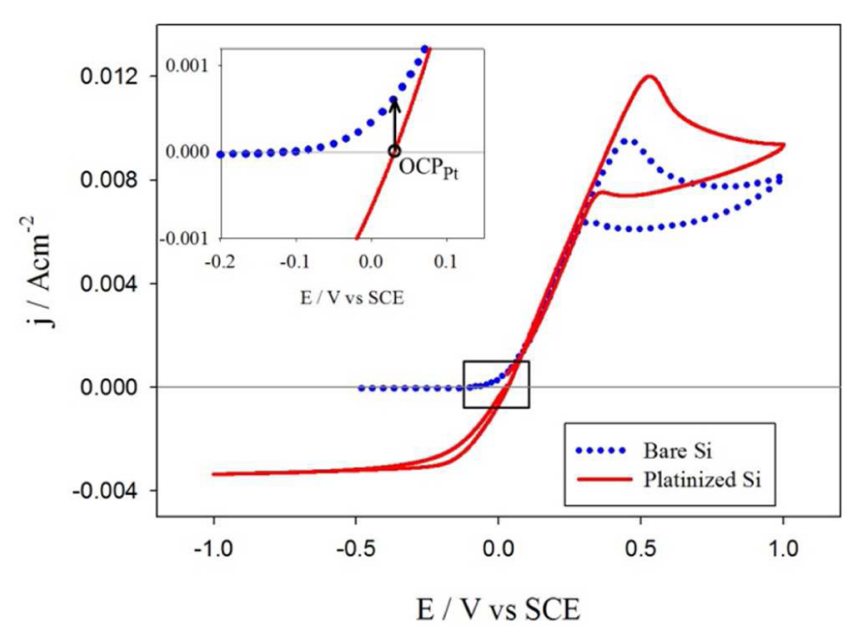

Figure 4. Cyclic voltammetric responses for bare (blue dotted line) and platinized $\mathrm{Si}$ (solid red line) in the dark, in $\mathrm{HF} / \mathrm{H}_{2} \mathrm{O}_{2}$ at $\rho=0.75$. Inset: enlarged image of the OCP zone. Sweep rate $=50 \mathrm{mV} / \mathrm{s}$.

the attainment of $J_{\mathrm{PS}}\left(\sim 9 \mathrm{~mA} / \mathrm{cm}^{2}\right.$, forward scan $)$, followed by the electropolishing regime ( $\mathrm{HF}$ diffusion control).

Under cathodic polarization below OCP, the current density is close to zero. On the other hand, the current/potential response of platinized $\mathrm{Si}$ is fairly different: $J_{\mathrm{PS}}$ is higher $(12 \mathrm{~mA}$ / $\mathrm{cm}^{2}$ ), probably because of the higher surface area rapidly induced by MACE, and a noticeable cathodic current is recorded, with a plateau value attained below $-0.5 \mathrm{~V}$ vs SCE $\left(-3.3 \mathrm{~mA} / \mathrm{cm}^{2}\right)$. As reported by Kooji et al. in the case of HF/ $\mathrm{HNO}_{3}$ etching, this cathodic current obtained for a p-type $\mathrm{Si}$ sample in the dark can be attributed to the collection of $\mathrm{h}^{+}$ injected by the oxidizing agent, the plateau value being determined by kinetics. ${ }^{32}$ In the present case, a high level of injection is obtained when the reduction of $\mathrm{H}_{2} \mathrm{O}_{2}$ is catalyzed by $\mathrm{Pt}$. The lack of cathodic current in the absence of $\mathrm{Pt}$ is in agreement with the very low etch rate of $\mathrm{Si}$ in $\mathrm{HF} / \mathrm{H}_{2} \mathrm{O}_{2}$ solutions $(\mathrm{nm} / \mathrm{h}) .^{33}$

The inset of Figure 4 shows that at the OCP of platinized Si $\left(+0.03 \mathrm{~V}\right.$ vs SCE, circle), an anodic current $\left(\sim 0.5 \mathrm{~mA} / \mathrm{cm}^{2}\right)$ is obtained for bare Si (arrow). This implies that under MACE conditions with $\mathrm{Pt}$, porous Si formation will occur at any bare $\mathrm{Si} / \mathrm{HF}$ area and not only in the close surroundings of the Pt NPs. This situation is similar to that reported by Kelly et al. for porous $\mathrm{Si}$ formation with galvanic cells in $\mathrm{HF} / \mathrm{H}_{2} \mathrm{O}_{2}$ where the back surface of a Si wafer is fully metallized. ${ }^{14}$ Although MACE differs in the nanometric size of the metal contacts, the etching mechanisms and overall results are the same as for macroscopic galvanic cells. They imply however some interesting band modulation effects due to the embedment of the nanoscaled metal/Si junction within the much wider $\mathrm{Si} /$ electrolyte junction.

Local modifications of the band structures induced by the presence of metal NPs on the electrochemical properties of Si have already been reported by Nakato et al. for hydrogen photoevolution. ${ }^{34-36}$ They showed qualitatively that, depending on the NP size, specific electrochemical behavior can be expected. ${ }^{37,38}$ In the next section, we present a band bending modeling based on numerical simulations that gives a precise spatial description of the band structures of $\mathrm{Pt} / \mathrm{Si} /$ electrolyte junctions at the nanoscale which helps to further rationalize the mechanisms of MACE with Pt NPs. This kind of simulation studies has been reported by Rossi and Lewis for nanometer- scale $\mathrm{Ni}$ arrays on $\mathrm{Si}$ electrodes ${ }^{39}$ and by Huang et al. in the case of metal assisted electrochemical etching with Ag NPs on p-type Si under anodic polarization in HF solutions. The latter authors have shown that the modulation of the band bending results in the collection of $\mathrm{h}^{+}$around the Ag NPs and there promotes a localized $\mathrm{Si}$ dissolution with the formation of mesopores. ${ }^{40}$

Band Bending Modulation. Numerical simulations in 2D of the valence band modulation at the $\mathrm{Pt} / \mathrm{p}$-Si/electrolyte interfaces were carried out using SILVACO $@$ ATLAS, a TCAD simulation software (cf. section S3.1 in SI for more details). The modeled structure consists of a p-type Si substrate with a thickness of $100 \mu \mathrm{m}$ and a width of $0.1 \mu \mathrm{m}$, covered by a $12 \mathrm{~nm}$ large Pt contact in the middle, surrounded by two electrolyte contacts (a scheme is provided in SI, Figure S3).

Experimental Mott-Schottky (MS) plots of bare and platinized $\mathrm{Si} / \mathrm{HF}$ junctions were first recorded in order to extract the experimental parameters required for the simulations, i.e., the doping density and flat band potential values (Figure S2 in SI). The experimental data and the detailed procedure for flat band calculation can be found in SI (sections S2 and S3.2). The Si/electrolyte and Pt/Si interfaces were both modeled as metal/Si contacts with two different work functions. The fitting between simulated and experimental MS plots was optimal when setting the work function of the electrolyte $\left(W_{\mathrm{EL}}\right)$ and $\mathrm{Pt}\left(W_{\mathrm{Pt}}\right)$ at 4.5 and $5.6 \mathrm{eV}$, respectively. These values are consistent with those found in the literature for p-type $\mathrm{Si}$ in HF solutions (on the basis of OCP values ${ }^{41}$ ) and for polycrystalline $\mathrm{Pt}^{42}$ For macroscopic contacts on p-type $\mathrm{Si}$, work functions values of $4.5 \mathrm{eV}$ and $5.6 \mathrm{~V}$ give a rectifying (Schottky) contact and an ohmic contact, respectively.

Figure 5a shows a 3D plot of the Si conduction band (CB) and valence band $(\mathrm{VB})$ modulations around the $\mathrm{Pt} \mathrm{NP}$ for the system at equilibrium. A $2 \mathrm{D}$ projection of the $\mathrm{VB}$ energy in the $(\mathrm{x}, \mathrm{y})$ plane is displayed on the bottom plane of this graph, with the zero energy reference corresponding to $\mathrm{e}^{-}$and $\mathrm{h}^{+}$Fermi level (FL).

In the bulk of $\mathrm{Si}$, the equilibrium $\mathrm{CB}$ and $\mathrm{VB}$ energies are found at 0.93 and $-0.19 \mathrm{eV}$, respectively. The large difference between $W_{\mathrm{EL}}(4.5 \mathrm{eV})$ and $W_{\mathrm{Pt}}(5.6 \mathrm{eV})$ induces a modification of the band bending at the surface close to the NP. Away from the Pt NP, i.e., at the p-Si/electrolyte Schottky junction, the surface $\mathrm{VB}$ energy is $-0.67 \mathrm{eV}$, implying an energy barrier height of $0.48 \mathrm{eV}$ for $\mathrm{h}^{+}$of the bulk. On the contrary, beneath the $\mathrm{Pt} \mathrm{NP}$, the surface VB energy is positive (by up to +0.43 $\mathrm{eV}$ ), i.e., the $\mathrm{VB}$ is above the FL, indicating the presence of a strong accumulation layer of $\mathrm{h}^{+}$. This accumulation layer extends up to $\sim 4 \mathrm{~nm}$ in $\mathrm{Si}$, where the $\mathrm{VB}$ crosses the FL. Therefore, the contact made by a Pt NP of $12 \mathrm{~nm}$ to p-type Si remains ohmic, as it is the case at the macroscopic scale. Note that this accumulation layer of $\mathrm{h}^{+}$is consistent with etching in the electropolishing regime beneath $\mathrm{Pt}$ (core of the mesopore).

The $2 \mathrm{D}$ modulation of the $\mathrm{VB}$ at equilibrium is shown in Figure $5 \mathrm{~b}$. Here, the energy is referenced with respect to the bulk VB energy, where the VB is flat. Most of the modulation actually occurs in a region of the order of the NP size, the space charge region (SCR) of the $\mathrm{Si} /$ electrolyte junction (violet areas) being fully recovered after $\sim 25 \mathrm{~nm}$ from the NP borders.

In order to simulate the MACE process, the oxidizing power of $\mathrm{H}_{2} \mathrm{O}_{2}$ was mimicked by a positive polarization applied to $\mathrm{Pt}$ (against the electrolyte, cf. section S3 in SI for details). Figure $5 \mathrm{c}$ gives the $2 \mathrm{D}$ modulation of the $\mathrm{VB}$ under $+0.2 \mathrm{~V}$ and Figure 

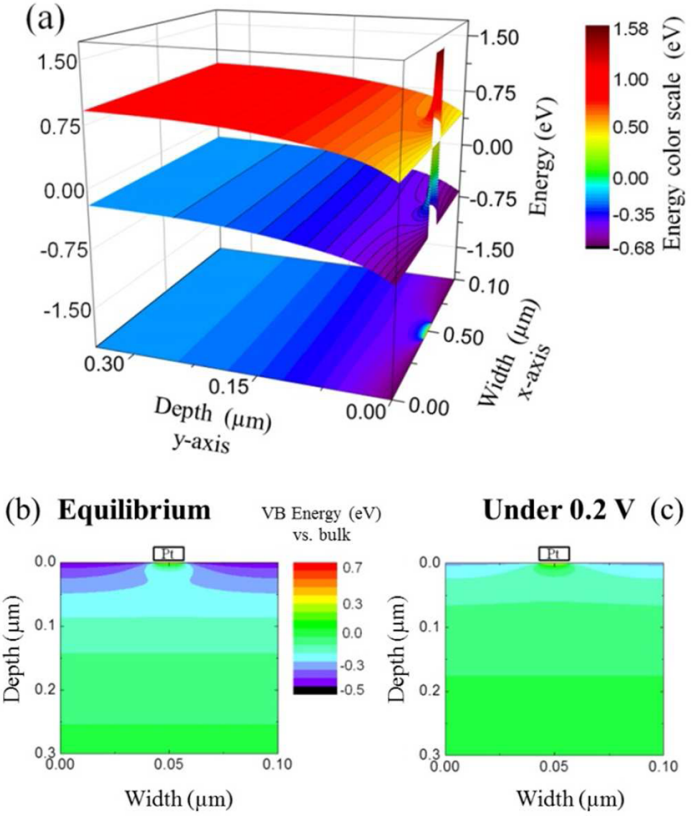

Figure 5. Modeling of the band bending of a $\mathrm{Pt} \mathrm{NP} / \mathrm{p}-\mathrm{Si} /$ electrolyte device. (a) $2 \mathrm{D}$ profiles of $\mathrm{CB}$ and $\mathrm{VB}$ energies (top and bottom planes, respectively) at the equilibrium $(0 \mathrm{~V})$. The $\mathrm{VB}$ energy is also projected on the bottom $(\mathrm{x}, \mathrm{y})$ plane. $(\mathrm{b}, \mathrm{c}) 2 \mathrm{D}$ profiles of the VB energies referenced to the VB bulk energy, (b) at equilibrium and (c) under $+0.2 \mathrm{~V}$ polarization (vs the electrolyte, cf. SI for details). The VB energy color scale is the same for (b) and (c).

6 the VB depth profiles ( $y$-direction) under equilibrium $(0 \mathrm{~V})$ and positive bias $(+0.1$ and $+0.2 \mathrm{~V})$ at two specific locations: (a) the middle of the Pt contact $(x=50 \mathrm{~nm})$ and (b) the electrolyte far from $\mathrm{Pt}(x=0 \mathrm{~nm})$.

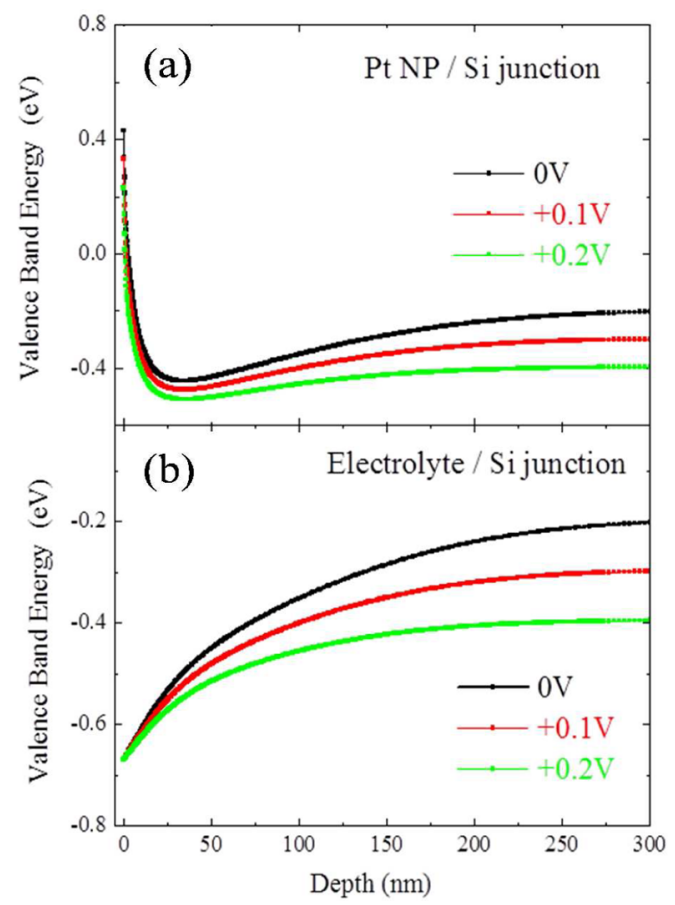

Figure 6. 1D profiles of the VB energy for different Pt polarization (a) under the Pt NP $(x=50 \mathrm{~nm})$ and (b) under the electrolyte $(x=0$ $\mathrm{nm})$.
Under positive bias, the major effect originating from the ohmicity of the $\mathrm{Pt}$ contact is that the entire voltage drop actually falls at the $\mathrm{p}$-Si/electrolyte interface. It is clear from Figure 6 (and also by comparing Figure $5 \mathrm{~b}$ and $\mathrm{c}$ ) that the VB in the bulk follows the applied polarization by the same extent. Consequently, the applied voltage (or the presence of $\mathrm{H}_{2} \mathrm{O}_{2}$ ) reduces the barrier height of the $\mathrm{Si} /$ electrolyte junction.

A more accurate "in situ" picture of MACE is given in Figure $7 \mathrm{a}$, which represents the simulated $2 \mathrm{D}$ profiles of both the $\mathrm{VB}$

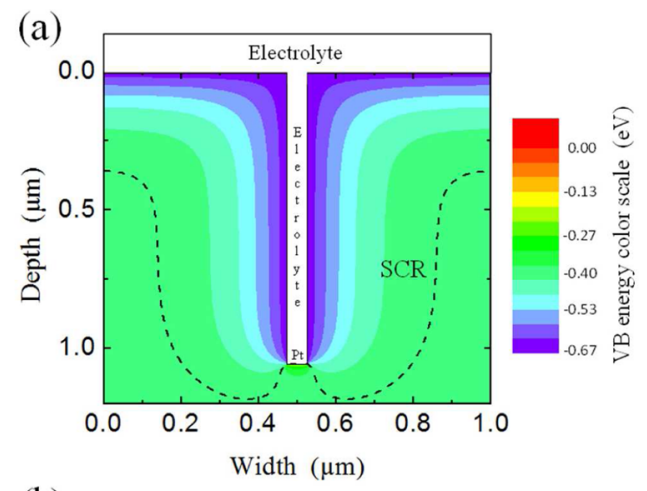

(b)

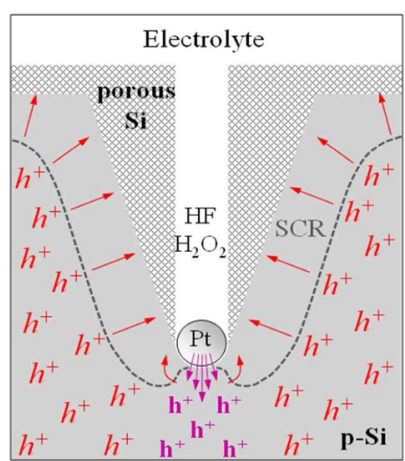

Figure 7. (a) Modeling of the VB bending in a $\mathrm{Pt} \mathrm{NP} / \mathrm{p}$-Si/Electrolyte device during MACE. The Pt NP was modeled by a $50 \mathrm{~nm}$ wide segment and buried at $1 \mu \mathrm{m}$ from the surface. A positive polarization of $0.2 \mathrm{~V}$ is applied to the Pt. Dashed lines indicate the limit of the SCR. (b) Scheme of cone-shaped pore formation by MACE with Pt NPs underlining $\mathrm{h}^{+}$injections and porous $\mathrm{Si}$ formation as deduced from the modeling. Bold $\mathrm{h}^{+}$are injected carriers, italic $\mathrm{h}^{+}$majority carriers driven to the electrolyte through bulk polarization.

and the space charge region (SCR) in Si and around the Pt NP once it has sunk into the substrate (cf. Figure S4 in SI for a closer view). For that, we have modeled a Pt NP with a size of $50 \mathrm{~nm}$, buried at the bottom of a $1 \mu \mathrm{m}$ deep mesopore without porous $\mathrm{Si}$, and polarized at $+0.2 \mathrm{~V}$. Figure $7 \mathrm{a}$ shows that the width of the SCR surrounding the NP is approximately $400 \mathrm{~nm}$ (this value depends on the doping concentration of $\mathrm{Si}$ ) and is constant almost from the pore tip to the surface. This should lead to a homogeneous supply of $\mathrm{h}^{+}$(hence porous $\mathrm{Si}$ formation rate) along the mesopore.

On the basis of the experimental results and numerical simulations, the scheme of Figure $7 \mathrm{~b}$ is proposed to rationalize the formation of cone-shaped pores by MACE with Pt NPs. According to this scheme, injected $\mathrm{h}^{+}$from Pt NPs (reduction of $\mathrm{H}_{2} \mathrm{O}_{2}$ ) spread in the bulk due to the ohmic nature of the Pt/ $\mathrm{Si}$ contact. This injection is split into two contributions: core etching in the electropolishing regime confined at the $\mathrm{Si} / \mathrm{Pt}$ interface and anodic polarization of the bulk leading to porous 
$\mathrm{Si}$ formation at the pore wall and at any $\mathrm{p}-\mathrm{Si} / \mathrm{HF}$ interface of the sample (e.g., front and back side). The porous Si layer thickness will be proportional to the etching time, i.e., large at the pore top and almost zero at the pore tip. Since the c-Si/ porous $\mathrm{Si}$ interface is relatively straight (cf. Figure 2) we can assume that (after a certain time) both etching processes occur at constant rates, i.e., there is a stable supply of $\mathrm{HF} / \mathrm{H}_{2} \mathrm{O}_{2}$ and a constant polarization of the bulk. The cone angle depends on the balance of etch rates such that an angle of $45^{\circ}$ would actually imply that the two etching process have equal rates.

On n-type $\mathrm{Si}$, the use of $\mathrm{Pt} \mathrm{NPs}$ for MACE in $\mathrm{HF} / \mathrm{O}_{2}$ has been studied by Yae et al. Compared to the above results for $\mathrm{p}$ type $\mathrm{Si}$, a significant difference is that less porous $\mathrm{Si}$ is formed around the pores and at the sample surface. ${ }^{43}$ We have also tested n-type Si MACE with $\mathrm{Pt}$ under our experimental conditions for p-type Si. In agreement with Yae et al., ${ }^{43}$ the quantity of porous $\mathrm{Si}$ formed at the surface and around the pores for the n-type sample was significantly lower than that for p-type. Moreover, no porous $\mathrm{Si}$ was found at the back side of the samples, whereas the p-type $\mathrm{Si}$ sample exhibits a few hundred $\mathrm{nm}$ thick layer of porous $\mathrm{Si}$ at the back side. These results agree well with a positive polarization of bulk Si under MACE with $\mathrm{Pt}$ which results in an anodic current only when majority carriers are $\mathrm{h}^{+}$.

Several reports on MACE with different metal catalysts have already considered $\mathrm{h}^{+}$injection and diffusion as key parameters to explain the (de)localized character of etching., ${ }^{79,21,22,44}$ For instance, a similar mechanism to the one exposed above, comprising vertical and sidewall etching, has been recently proposed by $\mathrm{Li}$. et al. in an attempt to correlate the 3D profile obtained with $\mathrm{p}$ - and $\mathrm{n}$-type $\mathrm{Si}$ samples during micro-MACE with $\mu \mathrm{m}$-sized straight-line patterns of $\mathrm{Au}$ as catalyst. ${ }^{19}$ In complement to these works, our results (i) demonstrate the ohmic nature of the nanocontacts made with Pt NPs (that should also apply in the case of $\mathrm{Au}$ ), (ii) rationalize the effect of $\mathrm{h}^{+}$injection in the case of p-type $\mathrm{Si}$ as a polarization of the bulk, and thus (iii) explain the various morphologies obtained by MACE (cone-shaped pores, tapered nanowires, etc.).

Application of an External Potential. In line with the mechanism proposed above, the application of an external potential during MACE can be envisaged as a way to counterbalance or enhance the polarization of the bulk induced by $\mathrm{Pt}$ nanocontacts. This means controlling the band bending at the $\mathrm{Si} /$ electrolyte junction, hence the formation of porous $\mathrm{Si}$ at the pore wall. MACE under external polarization was performed under the same conditions than regular MACE (3.63 M HF and 1.2 $\mathrm{M} \mathrm{H}_{2} \mathrm{O}_{2}, \rho=0.75$ ). Figure 8 shows the current/potential response obtained for platinized $\mathrm{Si}$ in $\mathrm{HF} /$ $\mathrm{H}_{2} \mathrm{O}_{2}$, together with SEM images of samples etched for $10 \mathrm{~min}$ at different cathodic or anodic potentials (highlighted by circles).

SEM observations show that upon increasing the potential from cathodic to anodic values, the resulting Si nanostructures evolve from a collection of straight mesopores to an array of well-defined cone-shaped pores. At $-1 \mathrm{~V}$ vs $\operatorname{SCE}(\mathrm{a})$, the porous $\mathrm{Si}$ layer around the core is thin and parallel to the wall (except at the tip) and becomes thicker as the potential is made more positive. The cone angle varies very significantly, from nearly $0^{\circ}$ at $-1 \mathrm{~V}$ up to $70^{\circ}$ at $+0.6 \mathrm{~V}$ vs SCE. The porous $\mathrm{Si}$ layer thickness at the surface follows the same trend, increasing from 2 to $6 \mu \mathrm{m}(\mathrm{b}-\mathrm{f})$.

These results can be readily understood taking into account that injected $\mathrm{h}^{+}$are preferentially collected in the bulk under
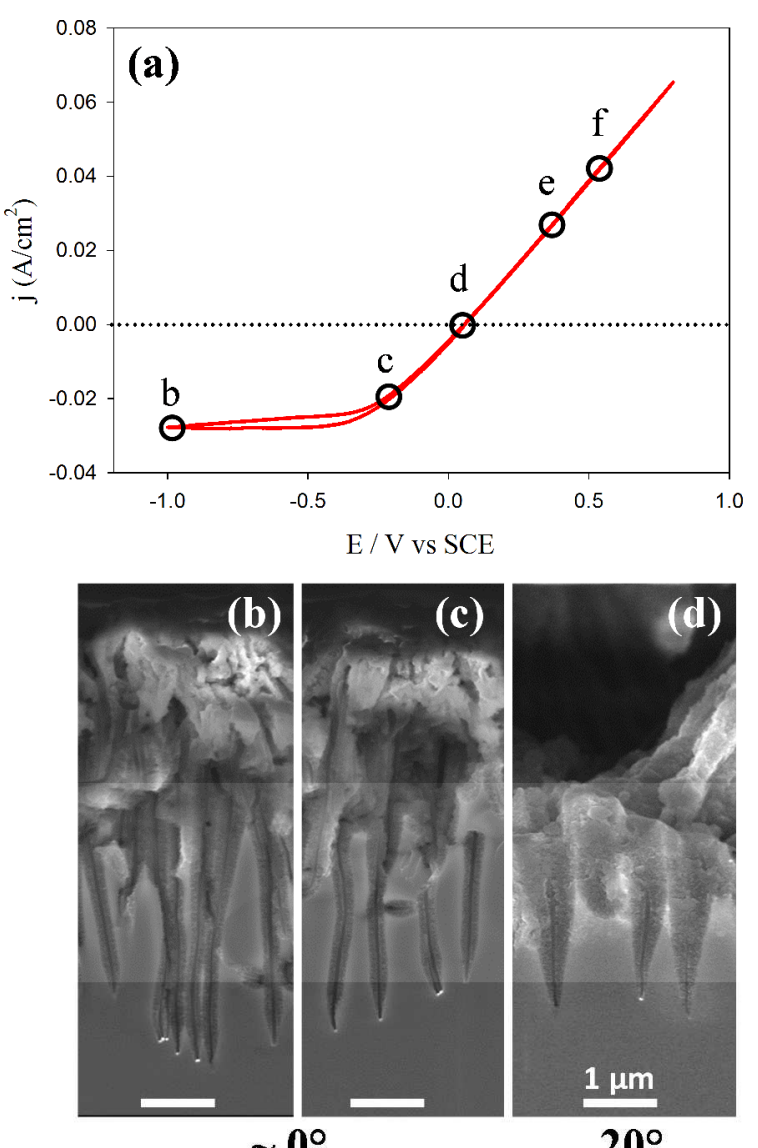

$\sim 0^{\circ}$

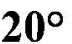

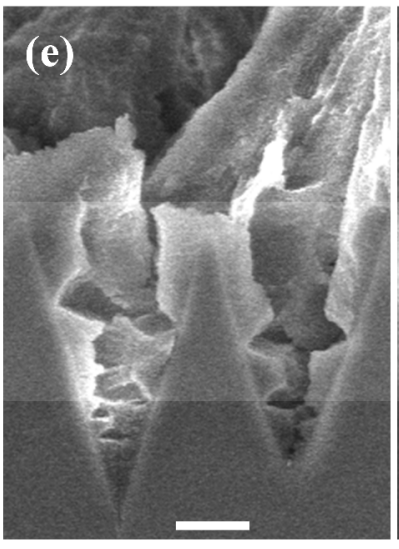

$35^{\circ}$

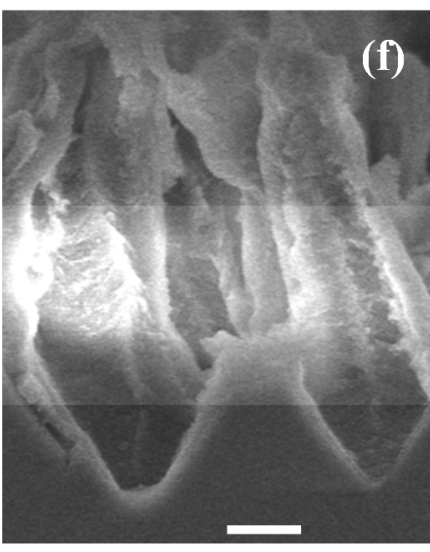

$70^{\circ}$
Figure 8. (a) Cyclic voltammetry of a platinized $\mathrm{p}-\mathrm{Si}(100)$ sample in $\mathrm{HF} / \mathrm{H}_{2} \mathrm{O}_{2}$ at $\rho=0.75$ with $[\mathrm{HF}]=3.63 \mathrm{M}$ and $\left[\mathrm{H}_{2} \mathrm{O}_{2}\right]=1.2 \mathrm{M}$. Sweep rate $=50 \mathrm{mV} / \mathrm{s}$. (b) - (f) SEM images in cross section after MACE with Pt NPs at different applied potentials: (b) $-1 \mathrm{~V}$, (c) -0.2 $\mathrm{V},(\mathrm{d})+0.05 \mathrm{~V}(\mathrm{OCP}),(\mathrm{e})+0.4 \mathrm{~V}$, (f) $+0.6 \mathrm{~V}$ vs SCE. Common scale bar for all images: $1 \mu \mathrm{m}$. The measured cone angles are reported below the images.

negative bias, whereas an additional $\mathrm{h}^{+}$current from the bulk is supplied to the $\mathrm{Si} /$ electrolyte interfaces under positive bias. The formation of porous $\mathrm{Si}$ at the pore walls and at the surface is then reduced in the first case and enhanced in the second.

Recently, $\mathrm{Li}$ et al. have reported on analogous results obtained with an electric bias-attenuated MACE method that could be applicable for manufacturing microelectronic devices. $^{45}$ With $\mathrm{p}-\mathrm{Si}$ and $\mathrm{Au}$ catalysts, they found that a 
negative electric polarization applied from the back side of Si substrates could avoid excessive etching occurring in traditional MACE. This is consistent with our experimental results and modeling because Au has a WF almost as large as Pt (5.47 vs $5.60 \mathrm{eV}$, respectively) and consequently $\mathrm{Si} / \mathrm{Au}$ contacts are ohmic as well (as confirmed by simulations made with $\mathrm{Si} / \mathrm{Au}$ NPs/electrolyte models but not shown here).

Chourou et al. have also reported on electrochemically assisted MACE of $\mathrm{p}^{-}$-type Si $(10-30 \mathrm{ohm} . \mathrm{cm})$ in HF $4.5 \mathrm{M}$ and $\mathrm{H}_{2} \mathrm{O}_{2} 0.9 \mathrm{M}(\rho=0.83)$ with Pt NPs and a superimposed anodic current of 1 to $2 \mathrm{~mA} / \mathrm{cm}^{2} .^{21}$ In this case, straight pores with a cone angle of $\sim 5^{\circ}$ are formed. In contrast, etching at very small anodic current close to OCP leads to much more opened cone shaped pores $\left(25^{\circ}\right)$ in our case. We assume that the main reason for these differences is related to the doping level of $\mathrm{Si}$. With $\mathrm{p}^{-}$-type $\mathrm{Si}$, a large space charge layer at the bottom of the pores and a depletion of carriers between them can be expected. Hence, the collection of $\mathrm{h}^{+}$should occur preferentially at the pore tip rather than at the pore walls and favor an in-depth growth.

Surface Texturization. The ability to vary the pore angle without constraint is interesting in the frame of $\mathrm{Si}$ surface texturization. This process aims at reducing the reflectance to improve light absorption in photodetectors and solar cells by creating surface morphologies that forces the incident light to bounce back onto the device surface, and hence to interact with the material, rather than be directly reflected. A well-known example is the elaboration of a network of inverted squarebased pyramids for monocrystalline (100) oriented Si solar cells. The walls and the angle of the pyramid $\left(54.7^{\circ}\right)$ are defined by the intersection of (111) planes revealed during an alkaline etching subsequent to a lithographic process. A lot of work is devoted to find surface treatments leading to macrostructures with higher aspect ratio (i.e., lower opening angles) to improve light coupling by increasing the number of light bounces.

In this context, a polarization of $+0.4 \mathrm{~V}$ vs SCE was found to be optimal for the reduction of reflectance. SEM images of sample surface morphology after MACE under $+0.4 \mathrm{~V}$ vs SCE and porous $\mathrm{Si}$ removal in $\mathrm{HNO}_{3} / \mathrm{HF}$ 99:1 V:V (5 min), are given in Figure 9a,b. Well-defined cone-shaped pores with an angle of $\sim 35^{\circ}$, corresponding to an aspect ratio (D/W) of 1.6, are covering the whole sample surface. The spread in size is relatively large, with the diameter (depth) ranging from 0.5 to 5 $\mu \mathrm{m}(0.8$ to $8 \mu \mathrm{m})$. Because such morphologies are difficult to obtain even with advanced plasma etching techniques, MACE with $\mathrm{Pt}$ has therefore a strong potential for $\mathrm{Si}$ surface structuration. These structures advantageously reduce the surface reflectance down to $3 \%$ in the 500-1000 $\mathrm{nm}$ range, as can be seen on the reflectance spectrum of Figure $9 \mathrm{~d}$ (circles). This reflectance value compares favorably with state of the art texturization techniques for $\mathrm{Si}$, such as inverted square-based pyramids arrays $(\mathrm{R} \sim 9 \%)$ used in record efficiency solar cells. ${ }^{46}$

The reflectance of this surface was modeled by using a ray tracing program presented in a previous publication. ${ }^{47}$ In this model, the surface is represented using a regular honeycomb formed of inverted hexagonal pyramids with $35^{\circ}$ opening angles (Figure 9c), which is obviously an idealized description of the real sample. Figure $9 \mathrm{~d}$ presents the comparison between modeled and measured reflectance for this particular surface, together with that corresponding to polished $\mathrm{Si}$, taken as reference. For the polished Si surface, the agreement between
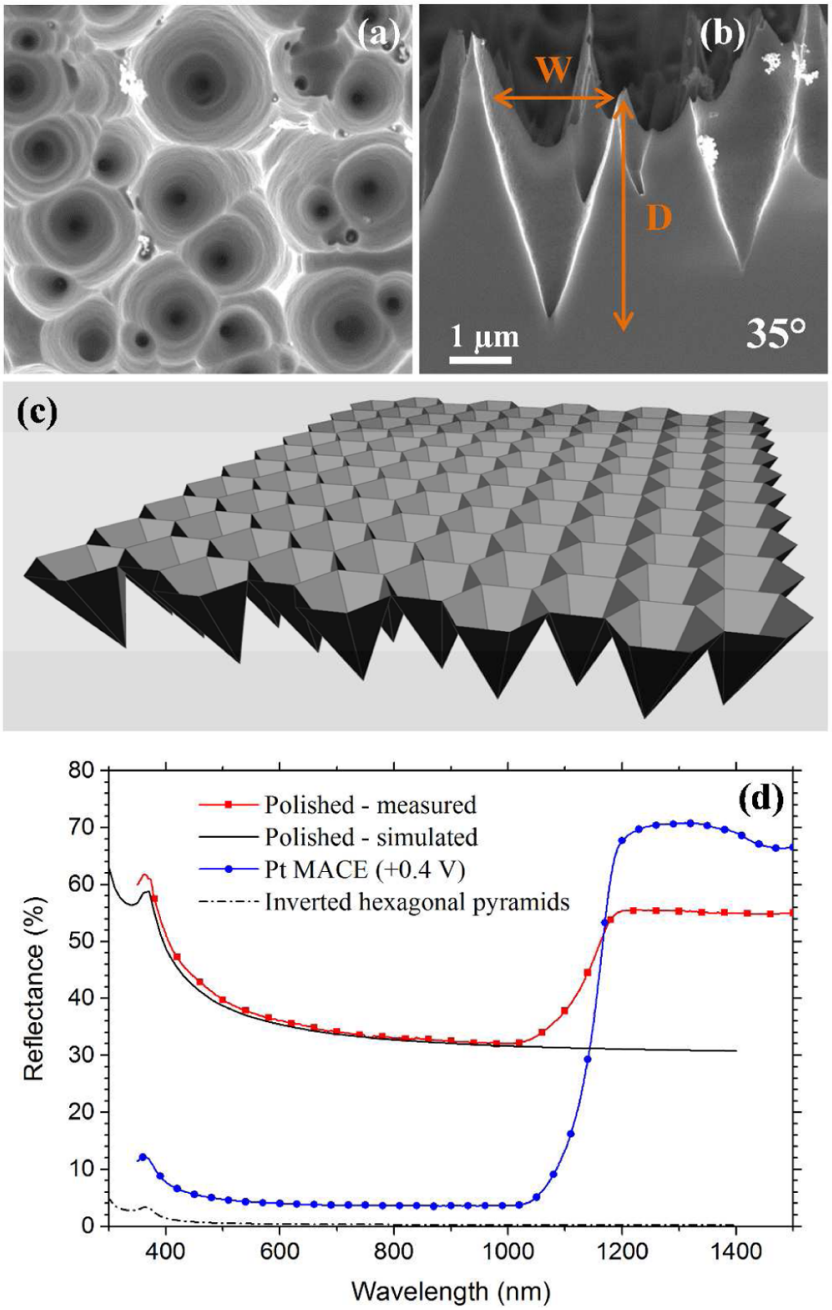

Figure 9. (a) and (b) Plain and cross sectional SEM images of (100) p-type Si samples after MACE with Pt NPs at $+0.4 \mathrm{~V}$ vs SCE and porous $\mathrm{Si}$ removal in $\mathrm{HNO}_{3}$ /HF. (c) Honeycomb structure of inverted hexagonal pyramids with $35^{\circ}$ opening angles used for ray tracing simulation. (d) Experimental (red squares and blue circles) and modeled (black solid and dashed lines) reflectance values obtained for polished and MACE texturized $\mathrm{Si}$.

simulation and experimental measurements is very good up to $\lambda$ $\geq 1000 \mathrm{~nm}$, since the model assumes that all the light penetrating $\mathrm{Si}$ is absorbed independently of the wavelength. However, in the infrared, the absorption coefficient of Si falls as the wavelength increases, and so, an increasing part of the incident light is reflected on the rear side of the substrate and exits by the front side, resulting in a large increase of the measured reflectance, as depicted by the experimental spectra. This limitation of the model for $\lambda \geq 1000$ is not detrimental for its reliability at shorter $\lambda$.

Concerning the textured surface, as only perfect and regular hexagonal pyramids are considered to mimic the cone-shaped pore morphology, the values of reflectance provided by the model are lower than those exhibited by the real surface $(0.34$ vs $3.7 \%$ at $700 \mathrm{~nm}$, respectively). Taking into consideration that the surface obtained experimentally is not homogeneously etched, with some distribution of etching angles and a small fraction which can be considered as nearly planar (cf. Figure $9 a, b)$, the measured reflectance is actually a weighted sum of the reflectance of different parts of the surface. For example, 
setting $10 \%$ of planar surface in the model would be sufficient to obtain an identical value of reflectance for simulation and experiments in the visible part of the spectrum. These results suggest that a better control of the experimental conditions during MACE, for example of the density and spatial distribution of the Pt NPs, could yield textures with even lower reflectance than 3\%. Current efforts are being developed in our laboratory to pursue this goal with the aim to reach a reflectance below $1 \%$.

\section{CONCLUSION}

A comprehensive detailed study of MACE with Pt NPs has been presented, paying particular emphasis on the understanding of the electrochemical mechanisms governing the etching and the resulting pore morphology. For that purpose, a combination of electrochemical techniques and $2 \mathrm{D}$ band bending modeling, with a positively biased NP at the top and buried in the Si substrate has been used. This novel kind of simulation mimics the "real" etching conditions and it has proved to be a powerful tool to describe the band modulation at the nanoscale. In our opinion, the approach followed in this work should provide new insights on MACE with other metal nanocatalysts in the future. The results obtained experimentally and from simulations allow concluding that $\mathrm{h}^{+}$injection during MACE can be split into two contributions: core formation by direct dissolution of $\mathrm{Si}$ in contact with $\mathrm{Pt}$ and anodic polarization of the bulk with porous $\mathrm{Si}$ formation at the pore wall. These two simultaneous processes, and the resulting typical cone-shaped pore morphology, are a consequence of the ohmic nature of the Pt nanocontacts. Experiments in which an external polarization is applied during MACE have further confirmed these results and proved to be a remarkably simple and efficient method to achieve structures ranging from straight mesopores to cone-shaped macropores of controlled opening angle as the $\mathrm{Si}$ sample is biased from negative to positive potentials. High aspect ratio macropores obtained under moderate anodic bias leads to a reduction of the surface reflectance down to $3 \%$ in the $500-1000 \mathrm{~nm}$ wavelength range. This value is significantly lower than that obtained by state of the art texturization techniques (e.g., inverted pyramids with $\mathrm{R}$ $\sim 9 \%)$. A 3D ray tracing simulation indicates that even lower reflectance could be achieved with cone-shaped pore arrays. Under optimized metallization, we believe that this tunable structuration of Si by MACE with Pt NPs has the potential to provide Si reflectance below $1 \%$.

\section{ASSOCIATED CONTENT}

\section{S Supporting Information}

The Supporting Information is available free of charge on the ACS Publications website at DOI: 10.1021/acsami.6b09036.

Nanoparticle size distribution on p-type (100) Si surfaces, experimental Mott-Schottky plots, design of the $\mathrm{Pt} / \mathrm{Si} /$ electrolyte structure used for modeling, simulated Mott-Schottky plots and MACE of (111) oriented $\mathrm{Si}$ (PDF)

\section{AUTHOR INFORMATION}

Corresponding Author

*Phone: +331 497813 30; E-mail: bastide@icmpe.cnrs.fr.

Author Contributions

${ }^{\perp}$ E.T. and S.L.G. made equal contribution to the manuscript

\section{Notes}

The authors declare no competing financial interest.

\section{ACKNOWLEDGMENTS}

The authors acknowledge the support of the French Agence Nationale de la Recherche (ANR), under grant ANR-14-CE070005-01 (project PATTERN).

\section{REFERENCES}

(1) Yae, S.; Morii, Y.; Fukumuro, N.; Matsuda, H. Catalytic Activity of Noble Metals for Metal-Assisted Chemical Etching of Silicon. Nanoscale Res. Lett. 2012, 7 (1), 352.

(2) Huang, Z.; Geyer, N.; Werner, P.; de Boor, J.; Gösele, U. MetalAssisted Chemical Etching of Silicon: A Review: In Memory of Prof. Ulrich Gösele. Adv. Mater. 2011, 23 (2), 285-308.

(3) Yae, S.; Tashiro, M.; Abe, M.; Fukumuro, N.; Matsuda, H. High Catalytic Activity of Palladium for Metal-Enhanced HF Etching of Silicon. J. Electrochem. Soc. 2010, 157 (2), D90.

(4) Tsujino, K.; Matsumura, M. Boring Deep Cylindrical Nanoholes in Silicon Using Silver Nanoparticles as a Catalyst. Adv. Mater. 2005, 17 (8), 1045-1047.

(5) Greil, S. M.; Rappich, J.; Korte, L.; Bastide, S. In Situ PL and SPV Monitored Charge Carrier Injection During Metal Assisted Etching of Intrinsic a-Si Layers on c-Si. ACS Appl. Mater. Interfaces 2015, 7 (21), 11654-11659.

(6) Tsujino, K.; Matsumura, M. Helical Nanoholes Bored in Silicon by Wet Chemical Etching Using Platinum Nanoparticles as Catalyst. Electrochem. Solid-State Lett. 2005, 8 (12), C193-C195.

(7) Kolasinski, K. W. The Mechanism of Galvanic/metal-Assisted Etching of Silicon. Nanoscale Res. Lett. 2014, 9 (1), 1-8.

(8) Kolasinski, K. W. Electron Transfer during Metal-Assisted and Stain Etching of Silicon. Semicond. Sci. Technol. 2016, 31 (1), 014002.

(9) Zhang, Z.; Lerner, M. M.; Alekel, T.; Keszler, D. A. Formation of a Photoluminescent Surface on $\mathrm{n}-\mathrm{Si}$ by Irradiation Without an Externally Applied Potential. J. Electrochem. Soc. 1993, 140 (6), L97L98.

(10) Gorostiza, P.; Díaz, R.; Sanz, F.; Morante, J. R. Different Behavior in the Deposition of Platinum from HF Solutions on N- and p-Type (100) Si Substrates. J. Electrochem. Soc. 1997, 144 (12), 41194122.

(11) Gorostiza, P.; Díaz, R.; Anbu Kulandainathan, M.; Sanz, F.; Ramon Morante, J. Simultaneous Platinum Deposition and Formation of a Photoluminescent Porous Silicon Layer. J. Electroanal. Chem. 1999, 469 (1), 48-52.

(12) Li, X.; Bohn, P. W. Metal-Assisted Chemical Etching in HF/ H2O2 Produces Porous Silicon. Appl. Phys. Lett. 2000, 77 (16), 25722574.

(13) Chattopadhyay, S.; Li, X.; Bohn, P. W. In-Plane Control of Morphology and Tunable Photoluminescence in Porous Silicon Produced by Metal-Assisted Electroless Chemical Etching. J. Appl. Phys. 2002, 91 (9), 6134-6140.

(14) Ashruf, C. M. A.; French, P. J.; Bressers, P.; Kelly, J. J. Galvanic Porous Silicon Formation without External Contacts. Sens. Actuators, A 1999, 74 (1), 118-122.

(15) Xia, X. H.; Ashruf, C. M. A.; French, P. J.; Kelly, J. J. Galvanic Cell Formation in Silicon/Metal Contacts: The Effect on Silicon Surface Morphology. Chem. Mater. 2000, 12 (6), 1671-1678.

(16) Peng, K.; Wu, Y.; Fang, H.; Zhong, X.; Xu, Y.; Zhu, J. Uniform, Axial-Orientation Alignment of One-Dimensional Single-Crystal Silicon Nanostructure Arrays. Angew. Chem., Int. Ed. 2005, 44 (18), 2737-2742.

(17) Lee, C.-L.; Tsujino, K.; Kanda, Y.; Ikeda, S.; Matsumura, M. Pore Formation in Silicon by Wet Etching Using Micrometre-Sized Metal Particles as Catalysts. J. Mater. Chem. 2008, 18 (9), 1015-1020.

(18) Li, X.; Xiao, Y.; Yan, C.; Zhou, K.; Schweizer, S. L.; Sprafke, A.; Lee, J.-H.; Wehrspohn, R. B. Influence of the Mobility of Pt Nanoparticles on the Anisotropic Etching Properties of Silicon. ECS Solid State Lett. 2013, 2 (2), P22-P24. 
(19) Li, L.; Zhao, X.; Wong, C.-P. Charge Transport in Uniform Metal-Assisted Chemical Etching for 3D High-Aspect-Ratio Micro-and Nanofabrication on Silicon. ECS J. Solid State Sci. Technol. 2015, 4 (9), P337-P346.

(20) Lai, R. A.; Hymel, T. M.; Narasimhan, V. K.; Cui, Y. Schottky Barrier Catalysis Mechanism in Metal-Assisted Chemical Etching of Silicon. ACS Appl. Mater. Interfaces 2016, 8 (14), 8875-8879.

(21) Chourou, M. L.; Fukami, K.; Sakka, T.; Virtanen, S.; Ogata, Y. H. Metal-Assisted Etching of P-Type Silicon under Anodic Polarization in HF Solution with and without $\mathrm{H} 2 \mathrm{O} 2$. Electrochim. Acta 2010, 55 (3), 903-912.

(22) Chartier, C.; Bastide, S.; Lévy-Clément, C. Metal-Assisted Chemical Etching of Silicon in $\mathrm{HF}-\mathrm{H} 2 \mathrm{O} 2$. Electrochim. Acta 2008, 53 (17), 5509-5516.

(23) Li, Y.; Jiang, Y.; Chen, M.; Liao, H.; Huang, R.; Zhou, Z.; Tian, N.; Chen, S.; Sun, S. Electrochemically Shape-Controlled Synthesis of Trapezohedral Platinum Nanocrystals with High Electrocatalytic Activity. Chem. Commun. 2012, 48 (76), 9531-9533.

(24) Li, X. Metal Assisted Chemical Etching for High Aspect Ratio Nanostructures: A Review of Characteristics and Applications in Photovoltaics. Curr. Opin. Solid State Mater. Sci. 2012, 16 (2), 71-81.

(25) Lehmann, V. The Electrochemistry of Silicon: Instrumentation, Science, Materials and Applications; Wiley-VCH: Weinheim, 2002.

(26) Geyer, N.; Fuhrmann, B.; Huang, Z.; de Boor, J.; Leipner, H. S.; Werner, P. Model for the Mass Transport during Metal-Assisted Chemical Etching with Contiguous Metal Films As Catalysts. J. Phys. Chem. C 2012, 116 (24), 13446-13451.

(27) Azeredo, B. P.; Lin, Y.-W.; Avagyan, A.; Sivaguru, M.; Hsu, K.; Ferreira, P. Direct Imprinting of Porous Silicon via Metal-Assisted Chemical Etching. Adv. Funct. Mater. 2016, 26 (17), 2929-2939.

(28) Chemla, M.; Homma, T.; Bertagna, V.; Erre, R.; Kubo, N.; Osaka, T. Survey of the Metal Nucleation Processes on Silicon Surfaces in Fluoride Solutions: From Dilute HF to Concentrated NH4F Solutions. J. Electroanal. Chem. 2003, 559, 111-123.

(29) Bertagna, V.; Rouelle, F.; Chemla, M. An Improved Electrochemical Cell for the Characterization of Silicon/electrolyte Interfaces. J. Appl. Electrochem. 1997, 27 (10), 1179-1183.

(30) Turner, D. R. On the Mechanism of Chemically Etching Germanium and Silicon. J. Electrochem. Soc. 1960, 107 (10), 810-816. (31) Memming, R.; Schwandt, G. Anodic Dissolution of Silicon in Hydrofluoric Acid Solutions. Surf. Sci. 1966, 4 (2), 109-124.

(32) Kooij, E. S.; Butter, K.; Kelly, J. J. Silicon Etching in HNO3/HF Solution: Charge Balance for the Oxidation Reaction. Electrochem. Solid-State Lett. 1999, 2 (4), 178-180.

(33) Gondek, C.; Lippold, M.; Röver, I.; Bohmhammel, K.; Kroke, E. Etching Silicon with HF-H2O2-Based Mixtures: Reactivity Studies and Surface Investigations. J. Phys. Chem. C 2014, 118 (4), 2044-2051.

(34) Nakato, Y.; Ueda, K.; Yano, H.; Tsubomura, H. Effect of Microscopic Discontinuity of Metal Overlayers on the Photovoltages in Metal-Coated Semiconductor-Liquid Junction Photoelectrochemical Cells for Efficient Solar Energy Conversion. J. Phys. Chem. 1988, 92 (8), 2316-2324.

(35) Nakato, Y.; Yano, H.; Nishiura, S.; Ueda, T.; Tsubomura, H. Hydrogen Photoevolution at P-Type Silicon Electrodes Coated with Discontinuous Metal Layers. J. Electroanal. Chem. Interfacial Electrochem. 1987, 228 (1), 97-108.

(36) Hinogami, R.; Nakamura, Y.; Yae, S.; Nakato, Y. Modification of Semiconductor Surface with Ultrafine Metal Particles for Efficient Photoelectrochemical Reduction of Carbon Dioxide. Appl. Surf. Sci. 1997, 121-122, 301-304.

(37) Yae, S.; Kitagaki, M.; Hagihara, T.; Miyoshi, Y.; Matsuda, H.; Parkinson, B. A.; Nakato, Y. Electrochemical Deposition of Fine Pt Particles on N-Si Electrodes for Efficient Photoelectrochemical Solar Cells. Electrochim. Acta 2001, 47 (1), 345-352.

(38) Memming, R. Semiconductor Electrochemistry, 2nd ed.; WileyVCH Verlag GmbH: Weinheim, Germany, 2000; p 238-240..

(39) Rossi, R. C.; Lewis, N. S. Investigation of the Size-Scaling Behavior of Spatially Nonuniform Barrier Height Contacts to Semiconductor Surfaces Using Ordered Nanometer-Scale Nickel
Arrays on Silicon Electrodes. J. Phys. Chem. B 2001, 105 (49), 12303-12318.

(40) Huang, Z. P.; Geyer, N.; Liu, L. F.; Li, M. Y.; Zhong, P. MetalAssisted Electrochemical Etching of Silicon. Nanotechnology 2010, 21 (46), 465301

(41) Bertagna, V.; Plougonven, C.; Rouelle, F.; Chemla, M. P- and nType Silicon Electrochemical Properties in Dilute Hydrofluoric Acid Solutions. J. Electrochem. Soc. 1996, 143 (11), 3532-3538.

(42) Michaelson, H. B. The Work Function of the Elements and Its Periodicity. J. Appl. Phys. 1977, 48 (11), 4729-4733.

(43) Yae, S.; Kawamoto, Y.; Tanaka, H.; Fukumuro, N.; Matsuda, H. Formation of Porous Silicon by Metal Particle Enhanced Chemical Etching in HF Solution and Its Application for Efficient Solar Cells. Electrochem. Commun. 2003, 5 (8), 632-636.

(44) Li, X.; Xiao, Y.; Yan, C.; Song, J.-W.; Talalaev, V.; Schweizer, S. L.; Piekielska, K.; Sprafke, A.; Lee, J.-H.; Wehrspohn, R. B. Fast Electroless Fabrication of Uniform Mesoporous Silicon Layers. Electrochim. Acta 2013, 94, 57-61.

(45) Li, L.; Zhao, X.; Wong, C.-P. Deep Etching of Single- and Polycrystalline Silicon with High Speed, High Aspect Ratio, High Uniformity, and 3D Complexity by Electric Bias-Attenuated MetalAssisted Chemical Etching (EMaCE). ACS Appl. Mater. Interfaces 2014, 6 (19), 16782-16791.

(46) Franklin, E.; Fong, K.; McIntosh, K.; Fell, A.; Blakers, A.; Kho, T.; Walter, D.; Wang, D.; Zin, N.; Stocks, M.; Wang, E.-C.; Grant, N.; Wan, Y.; Yang, Y.; Zhang, X.; Feng, Z.; Verlinden, P. J. Design, Fabrication and Characterisation of a $24.4 \%$ Efficient Interdigitated Back Contact Solar Cell: 24.4\% Efficient Interdigitated Back Contact Solar Cell. Prog. Photovoltaics 2016, 24 (4), 411-427.

(47) Magnin, V.; Harari, J.; Halbwax, M.; Bastide, S.; Cherfi, D.; Vilcot, J.-P. Angle-Dependent Ray Tracing Simulations of Reflections on Pyramidal Textures for Silicon Solar Cells. Sol. Energy 2014, 110, $378-385$. 


\title{
Tunable surface structuration of silicon by metal assisted chemical etching with $\mathbf{P t}$ nanoparticles under electrochemical bias
}

\author{
Encarnación Torralba ${ }^{*}{ }^{\dagger}$, Sylvain Le Gall ${ }^{*}{ }^{\ddagger}$, Raphaël Lachaume ${ }^{\ddagger}$, Vincent Magnin ${ }^{\S}$, Joseph \\ Harari $^{\S}$, Mathieu Halbwax ${ }^{\S}$, Jean-Pierre Vilcot ${ }^{\S}$, Christine Cachet-Vivier ${ }^{\dagger}$, Stéphane Bastide* \\ $\dagger$
}

† Institut de Chimie et des Matériaux Paris-Est, CNRS, Université Paris-Est, 2-8 rue Henri Dunant, 94320 Thiais, France

$\$$ Group of electrical engineering - Paris, UMR CNRS 8507, Centrale Supélec, Univ. ParisSud, Université Paris-Saclay, Sorbonne Universités, UPMC Université Paris 06, 3 \& 11 rue Joliot-Curie, Plateau de Moulon 91192 Gif-sur-Yvette CEDEX, France

$\S$ Institut d'Électronique, de Microélectronique et de Nanotechnologie, UMR CNRS 8520, Université de Lille 1 - Sciences et Technologies, Avenue Henri Poincaré, CS 60069, 59652 Villeneuve d'Ascq cedex, France

* To whom correspondence should be addressed. Phone:+33 01497813 30, E-mail: bastide@icmpe.cnrs.fr 


\section{S1. Nanoparticle size distribution}

The size distribution of Pt NPs obtained on p-type (100) Si surfaces by immersion in an aqueous solution of $1 \mathrm{mM} \mathrm{H}_{2} \mathrm{PtCl}_{6}$ and $90 \mathrm{mM} \mathrm{HF}$ for $120 \mathrm{~s}$ is presented in Figure S1. The feret diameter has been measured from SEM images processing using the software ImageJ. The average diameter is 50 $\mathrm{nm}$ and the Pt coverage $12 \%$.

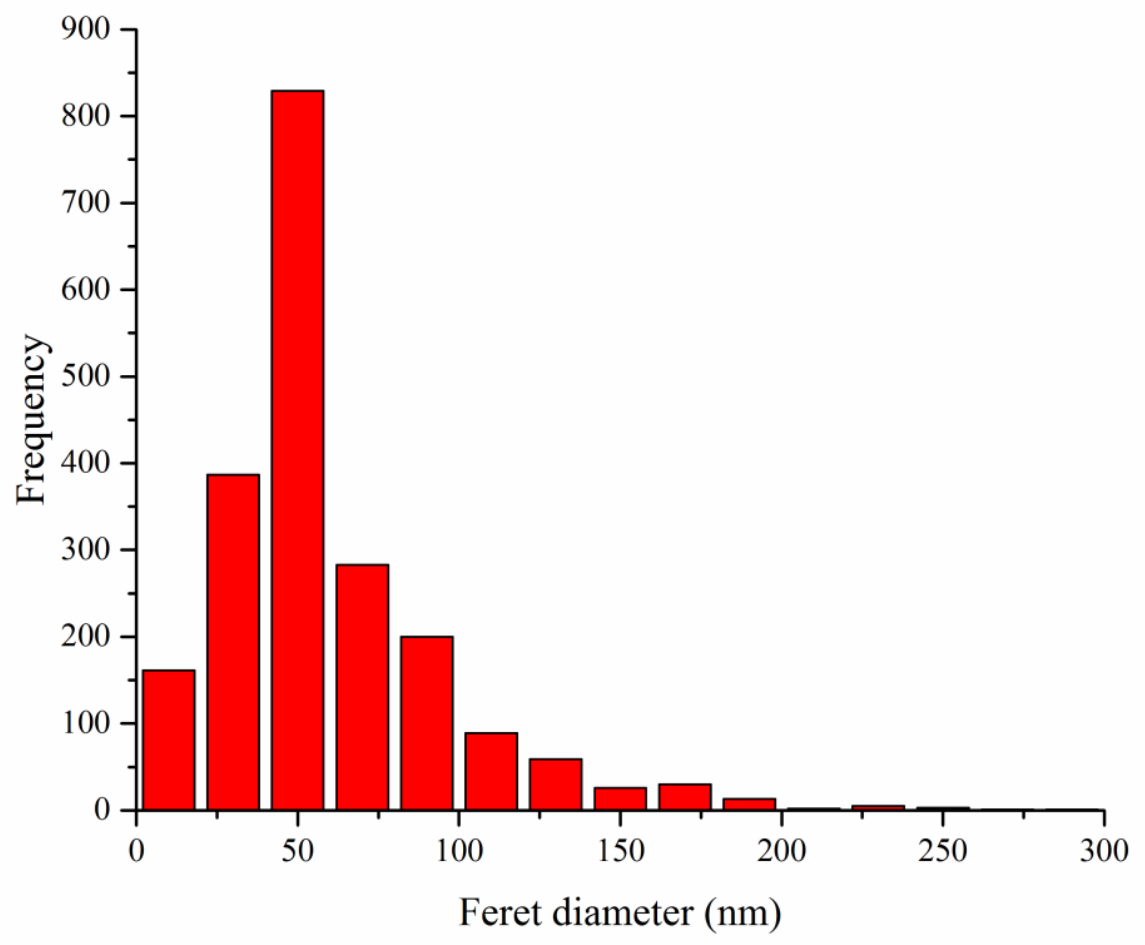

Figure S1. Feret diameter of the Pt NPs obtained by electroless Pt deposition in $1 \mathrm{mM} \mathrm{H}_{2} \mathrm{PtCl}_{6}$ and 90 $\mathrm{mM}$ HF for $120 \mathrm{~s}$, as deduced from SEM observations and image processing with the software ImageJ.

\section{S2. Experimental Mott-Schottky plots}

In the depletion regime, the capacitance $C$ of a metal/semiconductor (Schottky) junction can be described by the Mott-Schottky (MS) equation: ${ }^{1}$

For p-type

$$
\frac{1}{C^{2}}=\frac{2}{\varepsilon_{r} \varepsilon_{0} A^{2} e N_{A}}\left[-\left(V-V_{f b, p}\right)-\frac{k_{B} T}{e}\right]
$$

For n-type

$$
\frac{1}{C^{2}}=\frac{2}{\varepsilon_{r} \varepsilon_{0} A^{2} e N_{D}}\left[\left(V-V_{f b, n}\right)-\frac{k_{B} T}{e}\right]
$$

where $N_{A}$ and $N_{D}$ represent the doping densities for p-type and n-type respectively, $\varepsilon_{\mathrm{r}}$ is the relative permittivity of the semiconductor, $\varepsilon_{0}$ the vacuum permittivity, $A$ the electrode surface area, $V$ the applied potential, $V_{f b, p}$ and $V_{f b, n}$ the flat-band potentials for $\mathrm{p}$ and n-type, $e$ the elementary charge, $k_{B}$ the Boltzmann constant and $T$ the working temperature. 
The slope and the ordinate of the linear MS plots allow the experimental determination of the flat-band potential and doping density of a given semiconductor, two important parameters to describe its physical properties and required to perform the band bending simulations depicted in this work.

Figures S2(a) and S2(b) show the MS plots obtained respectively for platinized and bare ntype and p-type $\mathrm{Si}$ in contact with a solution of $\mathrm{HF}$ at $3.63 \mathrm{M}$. Although several frequencies were applied giving comparable doping densities and flat band potential values, only the MS plots measured at $50 \mathrm{kHz}$ are shown for the sake of clarity.
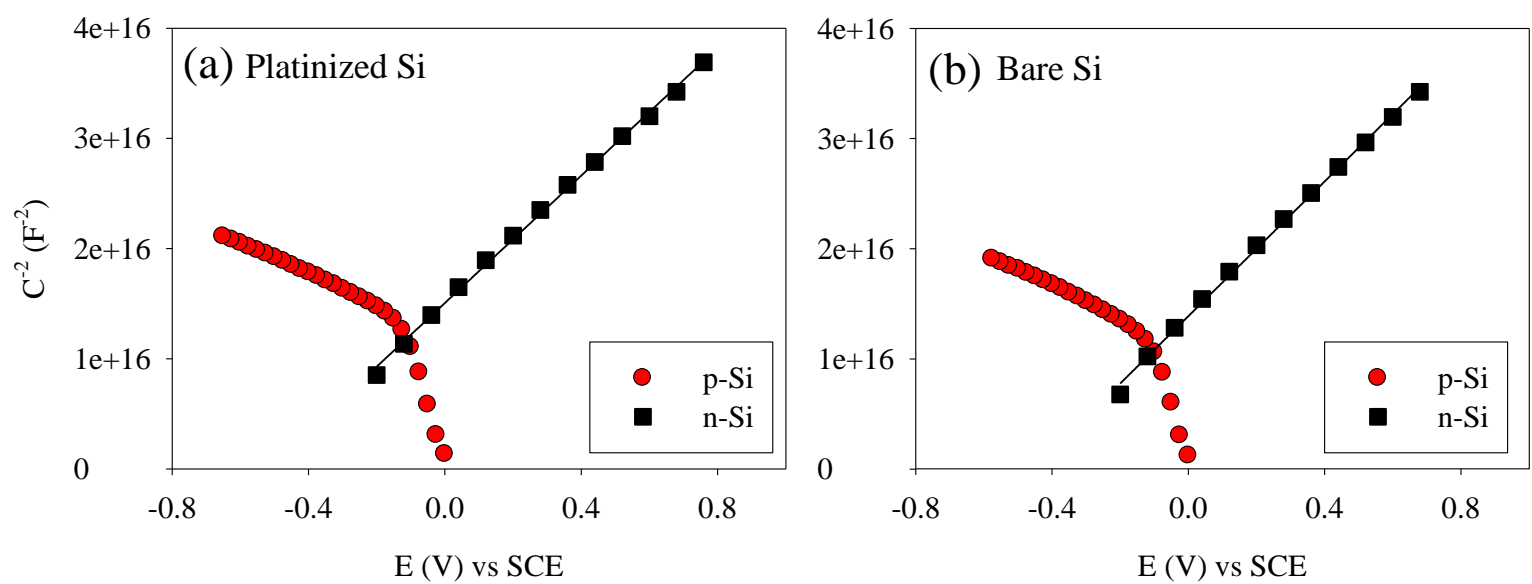

Figure S2. MS plots (1/ $\mathrm{C}^{2}$ vs E) recorded for platinized (a) and bare (b) $\mathrm{Si}(100)$, $\mathrm{p}$ and $\mathrm{n}$ doped (red circles and black squares, respectively) in contact with a solution of $\mathrm{HF}$ at $3.63 \mathrm{M}$ at a frequency of 50 KHz. Solid lines represent the linear fittings. All measurements were performed in the dark under Ar atmosphere. The resistivity of both $\mathrm{p}$ and $\mathrm{n}$ type samples was $1-3 \Omega \mathrm{cm}$.

The doping densities calculated from MS plots are $\mathrm{N}_{\mathrm{D}}=2.3 \times 10^{15} \mathrm{~cm}^{-3}$ and $\mathrm{N}_{\mathrm{A}}=5.6 \times 10^{15} \mathrm{~cm}^{-3}$ (Table S1), in good agreement with the resistivity ranges indicated by the supplier: $1.6-5.0 \times 10^{15} \mathrm{~cm}^{-3}$ for n-type Si and $4.7 \times 10^{15}-1.5 \times 10^{16} \mathrm{~cm}^{-3}$ for p-type Si.

It is well known that $V_{f b}$ measurements of Si in HF from MS plots are only reliable with n-type $\mathrm{Si}^{2}$. In the case of p-type $\mathrm{Si}$, deviations in flat band potential measurements are usually observed. According to the literature, a partial compensation or neutralisation of acceptors occurs at the surface due to the incorporation of hydrogen at large negative potentials and/or under light ${ }^{2}$. Consequently, $V_{f b, p}$ was calculated in an indirect way, by using $V_{f b, n}$ and $N_{D}$ obtained from the MS plots of n-type Si and applying the following expression: ${ }^{2}$

$$
V_{f b, p}=V_{f b, n}+\frac{1}{e}\left[E_{g}+k_{B} T \ln \left(\frac{N_{D} N_{A}}{N_{c} N_{v}}\right)\right]
$$

where $E_{g}$ is the band gap of $\mathrm{Si}, N_{c}=2.70 \times 10^{19} \mathrm{~cm}^{-3}$ and $N_{v}=1.04 \times 10^{19} \mathrm{~cm}^{-3}$ the effective density of states in the conduction and valence band, respectively. The calculated values are given in Table S1.

Table S1. Doping densities, OCP and $\mathrm{V}_{\mathrm{fb}}$ determined experimentally from the MS plots of bare and platinized $\mathrm{Si}$ ( $\mathrm{p}$ and n-type) in a $0.5 \mathrm{M} \mathrm{HF}$ aqueous solution under Ar bubbling and in the dark.

\begin{tabular}{|l|c|c|c|c|c|}
\hline & Bare n-Si & Pt n-Si & & Bare p-Si & Pt p-Si \\
\cline { 1 - 2 } \cline { 5 - 6 } $\mathrm{N}_{\mathrm{D}, \mathrm{A}}\left(\mathrm{cm}^{-3}\right)$ & $2.3 \times 10^{15}$ & -- & $5.6 \times 10^{15}$ & -- \\
\hline $\mathrm{OCP}(\mathrm{V}$ vs. SCE) & -0.26 & -0.28 & & -0.36 & -0.30 \\
\hline $\mathrm{V}_{\mathrm{fb}}$ (V vs. SCE) & -0.50 & -0.56 & & 0.18 & 0.13 \\
\hline
\end{tabular}

From bare $\mathrm{n}-\mathrm{Si} \mathrm{V}_{\mathrm{fb}, \mathrm{n}}$, we can estimate the experimental effective work function ( $v s$. vacuum level) of the electrolyte $\mathrm{W}_{\mathrm{EL}}$ using the following expression: 


$$
\mathrm{W}_{\mathrm{EL}}=\chi_{\mathrm{Si}}-\frac{k_{B} T}{e} \ln \left(\frac{N_{D}}{N_{c}}\right)-e V_{f b, n}^{0}
$$

where $\chi_{\mathrm{Si}}=4.05 \mathrm{eV}$ is the electronic affinity of $\mathrm{Si}$ and $\mathrm{V}_{\mathrm{fb}, \mathrm{n}}^{0}$ is the equilibrium flat band potential for which the energy reference is the equilibrium Femi-Level. $\mathbf{V}_{\mathrm{fb}, \mathrm{n}}^{0}$ can be deduced from the experimental $\mathrm{V}_{\mathrm{fb}, \mathrm{n}}$ by subtracting the measured OCP value (here $\mathrm{V}_{\mathrm{fb}, \mathrm{n}}^{0}=-0.24 \mathrm{~V}$ ). Using equation (S4), we find $\mathrm{W}_{\mathrm{EL}}=4.53 \mathrm{eV}$, which is compatible with values from the literature. ${ }^{2,3}$ This parameter will be fixed to $\mathrm{W}_{\mathrm{EL}}=4.5 \mathrm{eV}$ in the simulations of the band bending.

\section{S3. Band Bending Simulations}

The modelling has been performed using the commercial TCAD software Atlas from Silvaco $\odot{ }^{4}$. This simulator solves the physical equations governing the electrostatics (Poisson, electro-neutrality) and the transport of $\mathrm{e}^{-}$and $\mathrm{h}^{+}$(drift-diffusion) self-consistently on a 2D mesh.

\section{S3.1. Design of the Pt NP/Si/Electrolyte structure}

Figure $\mathrm{S} 3$ shows a scheme of the Electrolyte/Pt NP/p-Si structure used for the simulations displayed in Figure 5(a-d). This structure comprises a $100 \mu \mathrm{m}$ thick p-type $\mathrm{Si}$ substrate doped with $\mathrm{N}_{\mathrm{A}}=6 \times 10^{15} \mathrm{~cm}^{-3}$. The $\mathrm{Si}$ substrate is fitted with three metallic electrodes on top corresponding respectively to the Electrolyte, the Pt NP and again the Electrolyte (both Electrolyte electrodes being short-circuited). The total width (x-axis) of the structure is $0.1 \mu \mathrm{m}$. The Pt NP contact is positioned at the middle of the structure and covers $12 \%$ of the entire width. To avoid a short-circuit between the Electrolyte and the Pt NP electrodes, the latters are separated by a space of $1 \mathrm{~nm}$. A voltage can be applied between the Electrolyte (-) and $\mathrm{Pt}(+)$ electrodes to give account of the potential distribution and current flow during MACE (i.e. oxidation of $\mathrm{Si}$ at the level of the Electrolyte coupled to the reduction of $\mathrm{H}_{2} \mathrm{O}_{2}$ at the level of $\left.\mathrm{Pt}\right)$. An identical structure with a n-type $\mathrm{Si}$ substrate $\left(\mathrm{N}_{\mathrm{D}}=3 \times 10^{15} \mathrm{~cm}^{-}\right.$ ${ }^{3}$ ) has also been modelled.

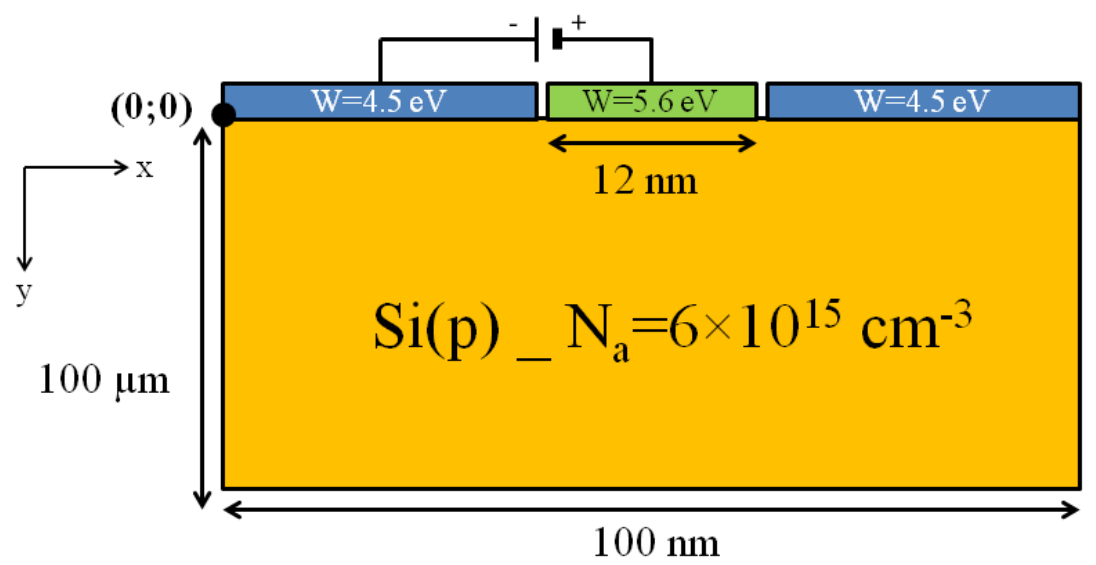

Figure S3. Structure used for the band bending modelling of the Pt NP/Si/Electrolyte junction at equilibrum and under an applied polarization mimicking the MACE process.

\section{S3.2 Simulation of Mott-Schottky plots}


In order to adjust the modelling with the real experimental conditions, it was necessary to set the work functions for the Electrolyte and the Metal. This was done by comparing the behavior of the modelled and experimental Electrolyte/Si (Pt) junctions through their MS plots (i.e. obtained with SILVACO and experimentally). The best agreement between simulations and experiments in terms of flat band potentials is reported in the Table S2.

Table S2. Flat band potentials obtained from experimental MS plots ( $0.5 \mathrm{M} \mathrm{HF}$, Ar, dark) and simulated MS plots (with the structure of Figure S3) for bare and platinized Si (p and n-type).

\begin{tabular}{|l|c|c|c|c|c|}
\hline & Bare n-Si & Pt n-Si & & Bare p-Si & Pt p-Si \\
\cline { 1 - 2 } \cline { 5 - 6 } \cline { 5 - 6 } & -0.24 & -0.28 & & +0.54 & +0.43 \\
\hline Simulated $V_{f b}(\mathrm{~V}) *$ & -0.22 & -0.34 & & +0.50 & +0.41 \\
\hline
\end{tabular}

* In the simulations, $V_{f b}$ values are given with respect to the Fermi level of the Metal or Electrolyte (at equilibrium), whereas in experiments, the $0 \mathrm{~V}$ reference is the SCE potential. To compare $V_{f b}$ in both systems, the experimental values are referenced to the measured OCP (equivalent to the Fermi level of the Metal or Electrolyte in the simulations). The OCP can however slightly fluctuate with time, for instance because of changes in the solution $\left(\mathrm{O}_{2}\right.$ concentration) or in the surrounding light.

In this set of data, the Electrolyte is modelled as a metal with an effective work function $\mathrm{W}_{\mathrm{EL}}=4.5 \mathrm{eV}$. The doping densities of bare n-type and p-type $\mathrm{Si}$ are $\mathrm{N}_{\mathrm{D}}=3 \times 10^{15} \mathrm{~cm}^{-3}$ and $\mathrm{N}_{\mathrm{A}}=6 \times 10^{15}$ $\mathrm{cm}^{-3}$. In the case of platinized $\mathrm{Si}$, the Pt work function used is $\mathrm{W}_{\mathrm{Pt}}=5.6 \mathrm{eV}$, in agreement with the literature ${ }^{5}$, and the Pt coverage is $12 \%$ as deduced from SEM observations.

The MS plots and $V_{f b}$ values calculated from the modelled structure and measured experimentally are in very good agreement. This indicates that the band bending modelling provides reliable information and can be used with confidence to explain the Pt based MACE process.

\section{S3.3 "In situ" modelling of MACE with Pt NPs}

Figure S4 represents a close view of the simulated 2D profiles in Si and around the Pt NP once it has sunk into the substrate. The Pt NP has a size of $50 \mathrm{~nm}$, is buried at the bottom of a $1 \mu \mathrm{m}$ deep mesopore and is polarized at $+0.2 \mathrm{~V}$ vs. the Electrolyte.

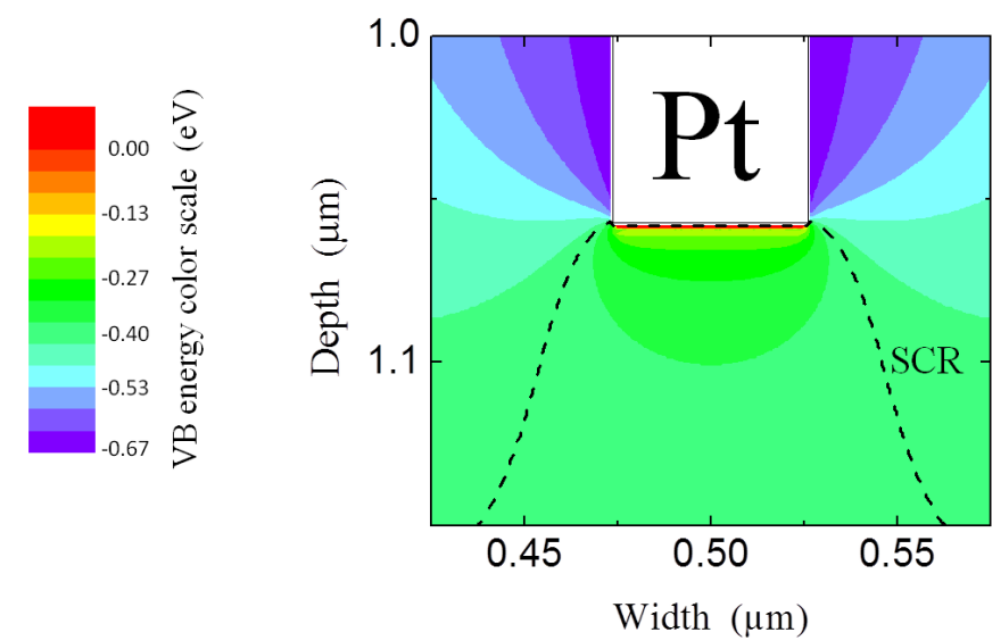

Figure S4. Close view of the "in situ" modelling of MACE at the level of a Pt NP (50 nm) that has digged a pore of $1 \mu \mathrm{m}$. The NP is polarized at $+0.2 \mathrm{~V}$ vs. the Electrolyte. 


\section{S4. MACE of (111) oriented Si with Pt NPs}

Figure S5 shows two SEM images taken at $45^{\circ}$ (unpublished results) of (a) p-type (111) oriented Si and (b) p-type multycristalline $\mathrm{Si}$ after MACE in $\mathrm{HF} / \mathrm{H}_{2} \mathrm{O}_{2}(\rho=0.5)$ with Pt NPs, followed by dissolution of porous $\mathrm{Si}$ in $\mathrm{HF} / \mathrm{HNO}_{3}$ to reveal the macropores. There is a clear dependance of the preferred etching directions followed by Pt NPs on the crystallographic orientation. With (111) Si, the macropores are oriented along the $\langle 100\rangle$ directions. With multicrystalline $\mathrm{Si}$, two adjacent grains exhibit macropores with very disctinct orientations on each side of the grain boundary.
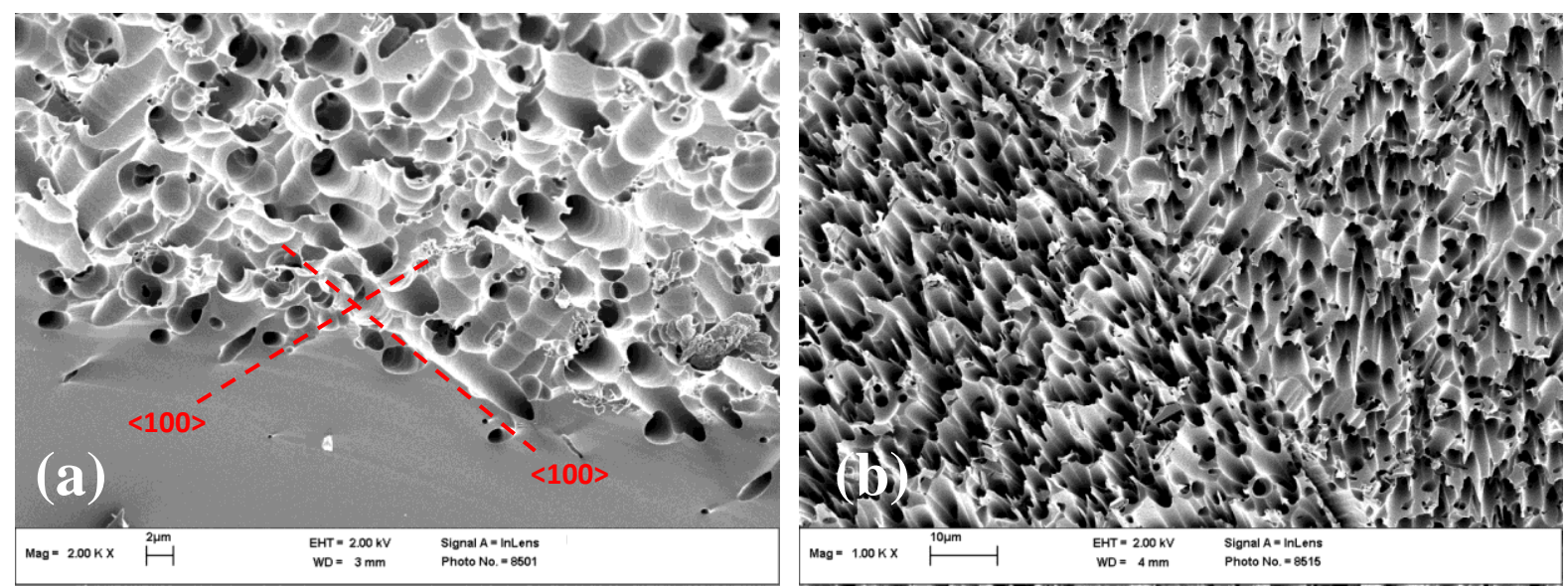

Figure S5. SEM image of (111) p-type Si (a) and multicrystalline p-type $\mathrm{Si}$ (b) after MACE in $\mathrm{HF} / \mathrm{H}_{2} \mathrm{O}_{2}(\rho=0.5)$ with Pt NPs and dissolution of porous $\mathrm{Si}$ in $\mathrm{HF} / \mathrm{HNO}_{3}$.

\section{References}

(1) Michalak, D. J.; Gstrein, F.; Lewis, N. S. Interfacial Energetics of Silicon in Contact with $11 \mathrm{M}$ $\mathrm{NH}_{4} \mathrm{~F}(\mathrm{aq})$, Buffered HF(aq), $27 \mathrm{M} \mathrm{HF}(\mathrm{aq})$, and $18 \mathrm{M} \mathrm{H}_{2} \mathrm{SO}_{4}$. J. Phys. Chem. C 2007, 111 (44), $16516-16532$.

(2) Ottow, S.; Popkirov, G. S.; Föll, H. Determination of Flat-Band Potentials of Silicon Electrodes in HF by Means of Ac Resistance Measurements. J. Electroanal. Chem. 1998, 455 (1-2), 29-37.

(3) Zhang, X. G. Electrochemistry of Silicon and Its Oxide, 1st ed; Springer International Publishing AG: Switzerland, 2001.

(4) Atlas User's Manual, Device Simulation Software. Silvaco International 2006.

(5) Michaelson, H. B. The Work Function of the Elements and Its Periodicity. J. Appl. Phys. 1977, 48 (11), 4729-4733. 